\title{
Logic of organic chemistry
}

\author{
Alexander Arndt ${ }^{1} \cdot$ Tom Kunde $^{1} \cdot$ Rainer Mahrwald $^{1}$ (i)
}

Received: 2 November 2015/Accepted: 21 December 2015/Published online: 6 February 2016

(C) Springer International Publishing Switzerland 2016

\begin{abstract}
A system of logic disconnection or construction of organic molecules is given to overcome serious problems in the study of organic chemistry. Based on the logic system of polar reactions of donors and acceptors several different reactions can be created to access a required target molecule. By a following careful analysis of these proposals several transformations can be detected as the preferred ones. Moreover, by the introduction of the "umpolung" principle additional options are given to synthesize a required molecule. These considerations were discussed in the 1,2-, 1,3-, 1,4-, 1,5- and 1,6-difunctional series.
\end{abstract}

Keywords Disconnection - Synthesis - Donor ·

Acceptor $\cdot$ Polar reaction $\cdot$ Umpolung

\section{Introduction}

\section{Why "logic of organic chemistry"}

To study organic chemistry is a job, comparable with learning a foreign language. To study foreign language one needs the vocabulary and the rules how to use the vocabulary-the grammar. Grammar is the logic (logical skeleton) of a language. Grammar and vocabulary interact while practicing a language.

The same is true for the understanding of organic chemistry. Chemical formulae (compounds) and their reactions produce the field of organic chemistry. As in language, the vocabulary

Rainer Mahrwald

rainer.mahrwald@rz.hu-berlin.de

1 Institute of Chemistry, Humboldt-University, Brook-Taylor Str. 2, 12489 Berlin, Germany of organic chemistry has to be learned. These are the formulae or rather the compounds in organic chemistry. In addition, hundreds of named reactions or mechanisms have to be memorized and even talented students are eventually overloaded with details and names. But the logic or the principles behind this vocabulary cannot be understood or understood by this kind of a learning process. Compounds or names alone does not provide a full understanding of organic chemistry, as this is true for learning reaction mechanism alone.

But there is hope. In contrast to the 6500 particular languages in the world, there is only one language of organic chemistry, only one logic of organic chemistry.

Several different procedures or methodologies have been developed to help students in this situation: classical learning of classes of compounds followed by reaction mechanism and later on advanced organic chemistry, or a defined mixing of these topics, and so on.

However, these approaches have not satisfied everyone and thus sometimes eccentric and strange approaches were generated. For a crossword puzzle to learn name reactions and name apparatuses see Ref. [1].

These considerations are supported by the following examples. The first example represents an excerpt of name reactions to construct a double bond.

Wittig-Horner reaction

Peterson olefination

McMurry reaction

Tebbe reaction

Julia olefination

Bamford-Stevens reaction

Cope elimination

Corey-Winter reaction

Perkin reaction

Prins reaction 
Ramberg-Bäcklund reaction

Robinson annulation

Wagner-Meerwein rearrangement

In addition, there are a great many of condensation processes: aldol condensation, Knoevenagel condensation, Hantzsch synthesis, Hofmann elimination, PaalKnorr-Pyrrole synthesis etc. These names contain no clues as to the mechanism and substrates used in these reactions.

Furthermore, retrosynthetic disconnections [2] of a target molecule represent the foundation of a successful multistep synthesis. This analysis cannot be accomplished using chemical formulas or name reactions alone. It is imperative to use both, the formulas and the logic of organic chemistry. A further example should illustrate these considerations. It would be very hard to understand that by the reaction sequence of

- Staudinger $[2+2]$ cycloaddition of cyclopentadiene and dichloroketene followed by

- reductive removal of chlorine

- Bayer-Villiger oxidation

- Prins reaction

- Swern oxidation

- Horner olefination and final

- Wittig reaction

an access to prostaglandins is given.

By evaluation of the retrosynthetic disconnection of reactions and substrates though one can easily understand the synthetic process to manufacture prostaglandins (Scheme 1).
Scheme 1 Retrosynthetic pathway of prostaglandins

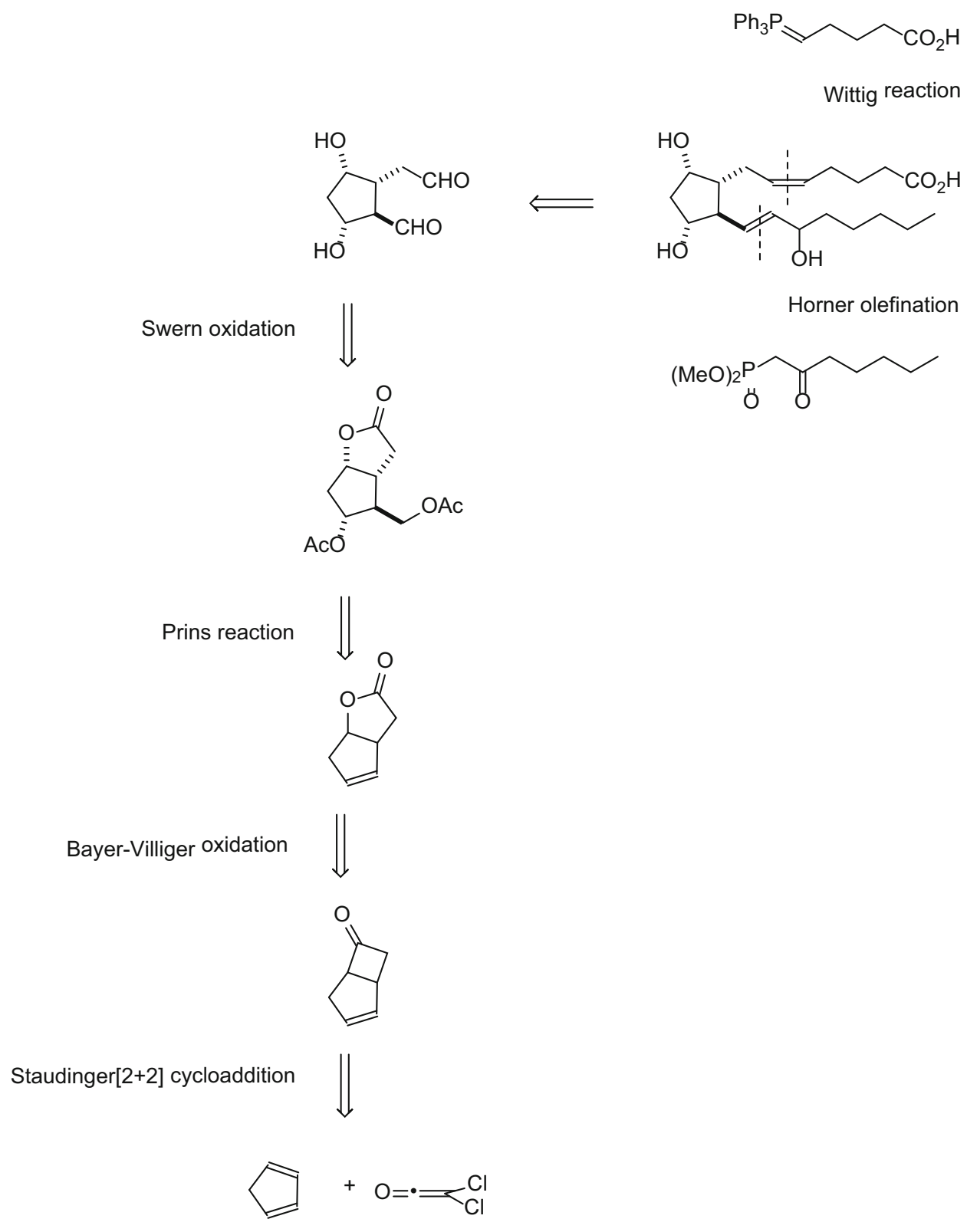


Or for an even more confusing, final example, a named reaction is a reaction step within a name reaction, as is true for the Amadori rearrangement, a part of the Maillard reaction. To overcome all these problems and to support students in their studies of organic chemistry, a survey (course) through the "logic of organic chemistry" is very helpful.

\section{What is "logic of organic chemistry"?}

Most of $\mathrm{C}-\mathrm{C}$ bond formation processes are polar reactions. A formal carbanion (donor, symbol $\rightarrow \mathbf{d}, \delta^{-}$) reacts with a formal carbocation (acceptor, symbol $\rightarrow \mathbf{a}, \delta^{+}$) to form a covalent carbon-carbon bond. Functional groups influence these donor and acceptor properties by their electronic nature. They install an alternating acceptor-donor reactivity network (pattern) along the carbon skeleton (backbone). This concept is very old and was probably generalized for the first time by Lapworth in 1898 [3, 4]. This natural reactivity is depicted in Scheme 2. From this Scheme can be seen that donor carbon atoms are characterized by even numbers, whereas acceptors have odd numbers (Schemes 3, 4). By inspection of donors a following reactive scheme can be drawn: $d^{2}, d^{4}, d^{6}$ to $d^{n}$

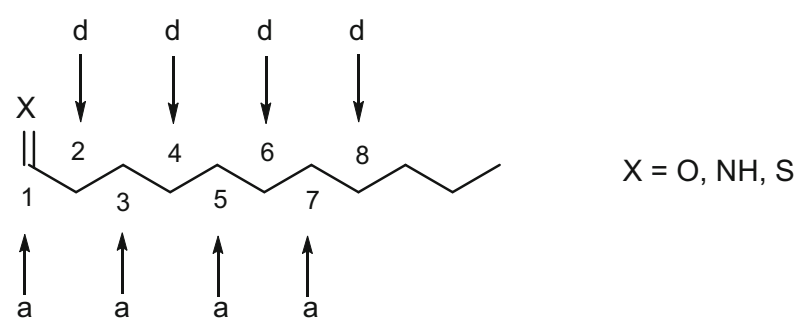

Scheme 2 Polarity pattern

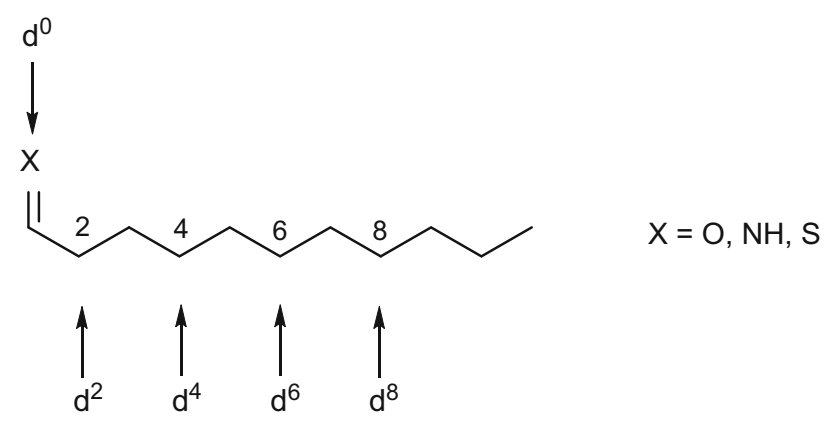

Scheme 3 Donor reactivity pattern

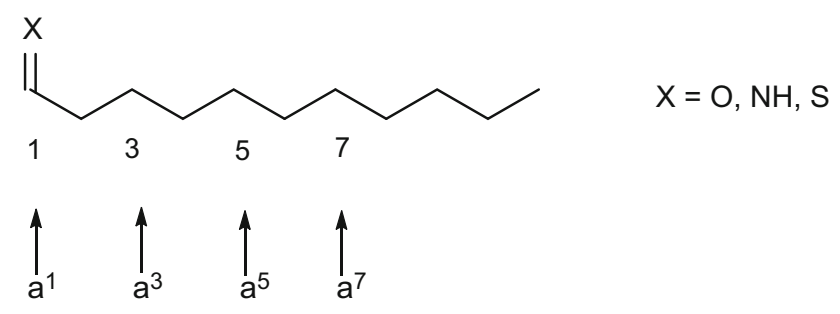

Scheme 4 Acceptor pattern

A similar network can be developed for acceptors: $\mathrm{a}^{1}$, $\mathrm{a}^{3}, \mathrm{a}^{5}$ to $\mathrm{a}^{n}$.

These species (donors or acceptors) are mostly not really existing molecules. These are idealized "structural units within a molecule that are related to possible synthetic operations" [5] and they are called synthons.

These synthons react in a polar fashion: a donor synthon reacts with an acceptor synthon to form a $\mathrm{C}-\mathrm{C}$ bond and vice versa.

As an example: $a^{1}+d^{1}$ or $d^{1}+a^{1}$ (see also Scheme 5).

Based on this simple alternate polarity scheme every carbon atom can be accessed to form a new $\mathrm{C}-\mathrm{C}$ bond, provided that the reactivities of both substrates match (donor/acceptor or acceptor/donor).

To evaluate the feasibility of a reaction path or in other words to organize a synthetic plan on the base of these polarity schemes retrosynthetic analysis has to be accomplished. This reversed synthetic procedure is called retrosynthesis, which can be done by theoretical disconnection of a target molecule into molecular pieces (synthons). In synthesis (the reversed way), equivalents of these synthons have to be found and should be reacted together by known and reliable transformations to give the target molecule. A double line arrow indicates the direction of retrosynthesis. The direction of a retrosynthetic arrow contrasts the direction of a reaction arrow.

These considerations should be illustrated by the synthesis of $\beta$-hydroxy ketones (1.3-difunctional compounds). By retrosynthetic disconnection two possibilities are found to disconnect $\beta$-hydroxy ketones (Scheme 5).

The $\mathrm{a}^{1}+\mathrm{d}^{2}$ approach to $\beta$-hydroxy ketone can be easily realized by the direct aldol reaction of propionaldehyde and methyl ethyl ketone (aldol reaction). The $\mathrm{d}^{2}+\mathrm{a}^{1}$ approach is connected with additional reaction steps, as demonstrated in Scheme 6. To overcome the problem of the inverted oxidation states, six additional reaction steps are necessary (Scheme 6). These steps are characterized by an extensive handling of orthogonal protective groups.

In addition to this natural reactivity, organic chemistry offers methods to change the donor into an acceptor and vice versa. This process is called "umpolung" (polarity inversion). An illustrative example is depicted in Scheme 7. 
Scheme 5 Retrosynthetic pathway to $\beta$-hydroxy ketones<smiles>CCC(O)C(=CI)C(C)=O</smiles><smiles>CCC(O)C(=CI)C(C)=O</smiles>

$d^{2}+a^{1}$<smiles>CCC(C)=O</smiles>

propionaldehyde + methyl ethyl ketone<smiles>CCC(=O)CC</smiles>

$\mathrm{Me}$ $a^{1}$<smiles>CCCCCC(C)C(C)C(C)C(C)C</smiles><smiles>CCC(O)C(C)C(C)O</smiles>

Scheme $6 d^{2}+a^{1}$ Approach to $\beta$-hydroxy ketones

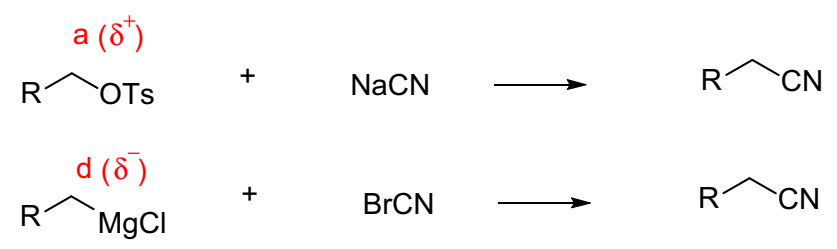

Scheme 7 "Umpolung” strategy

A tosylate (acceptor) reacts with sodium cyanide to give the expected nitrile. When used with a Grignard reagent (donor), this reaction requires the deployment of cyanogen bromide (acceptor), to yield the same nitrile.

Another example illustrates the different chemical behaviors of methyl ethyl ketone when used with "umpoled" reagents. A $\alpha$-alkylation is observed in reactions with a tosylate (acceptor), whereas a 1,2-addition is observed when used with a Grignard reagent (donor) (Scheme 8).

The "natural" (original) reactivity in molecules is changed by simple chemical manipulations [6]. This synthetic tool significantly increases the possible operations of the manual of organic chemistry. Note that "umpoled" donors have odd numbers and "umpoled" acceptor synthons are characterized by even numbers. For a comprehensive and systematic overview see Ref. [7] (Scheme 9).

A few selected examples for "umpolung" reactions are depicted in Scheme 10. Many of these manipulations come from metalorganic chemistry, e.g., the simple preparation of a Grignard reagent of an alkyl halide implies an "umpolung" process. Also, Wittig reactions or Horner olefinations are important examples of "umpolung" reactions.

Also, "umpolung" can be achieved by the addition of carbon fragments. Some examples of this series are
Scheme 8 Different outcome by applying natural and "umpoled" reagents

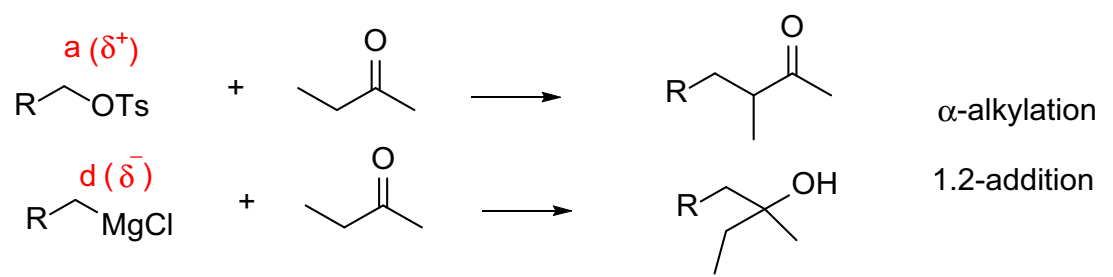




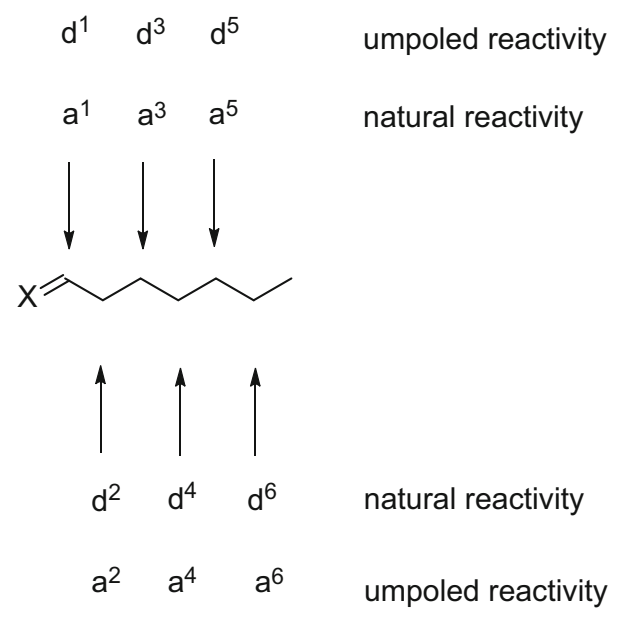

Scheme 9 Natural and umpoled reactivity

depicted in Scheme 11. The formation of cyanohydrins is an important method in the manual of "umpolung" reactions.

With this second series of $\mathrm{C}-\mathrm{C}$ bond formation processes - the "umpolung" reactions-we have a powerful tool in hands to overcome several serious problems of organic chemistry. The synthetic possibilities to access a defined target molecule will be extended considerably. From the logical point of view, there must exist for every reaction based on natural reactivities a reaction based on "umpoled" reactivities. In other words, a given product can be accessed in general by two modes-by reactions with natural substrates and by reactions with the corresponding "umpoled" substrates. By application of this concept the manual of synthetic possibilities is doubled. A traditional reaction $(d+a)$ can be also realized by the complementary "umpolung" strategy ("umpolung" of $d+a=a+d$ ). But both reactions based on natural reactivities as well reactions with the corresponding "umpoled" synthons yield the same product. This is depicted in Scheme 12.

These considerations will be explained in the example of the synthesis of $\beta$-hydroxy ketones in Scheme 13.

Mostly, there is one simple and direct access to realize this $\mathrm{C}-\mathrm{C}$ bond formation process. However, the alternatives to this simple and direct access are connected with more or less complex or extensive use of protection/deprotection and functional group interconversions (FGI). The choice of a synthetic route depends on the described difficulties, such as access to chemicals (reagents), costs of chemicals, etc. But one must state that the greater the number of disconnections, the greater the chance of a successful synthesis to a target molecule.

Schemes 14 and 15 illustrate these "umpoled" reactivities in action. For clarity we have used consistent and comparable substrates and reactions. These are the aldol reactions of Schemes 5 and 6. Also, "umpoled" aldehyde and ketone give an access to $\beta$-hydroxy ketones (Scheme 15).
Scheme 10 "Umpolung" by atom exchange. $\mathrm{M}=$ metal

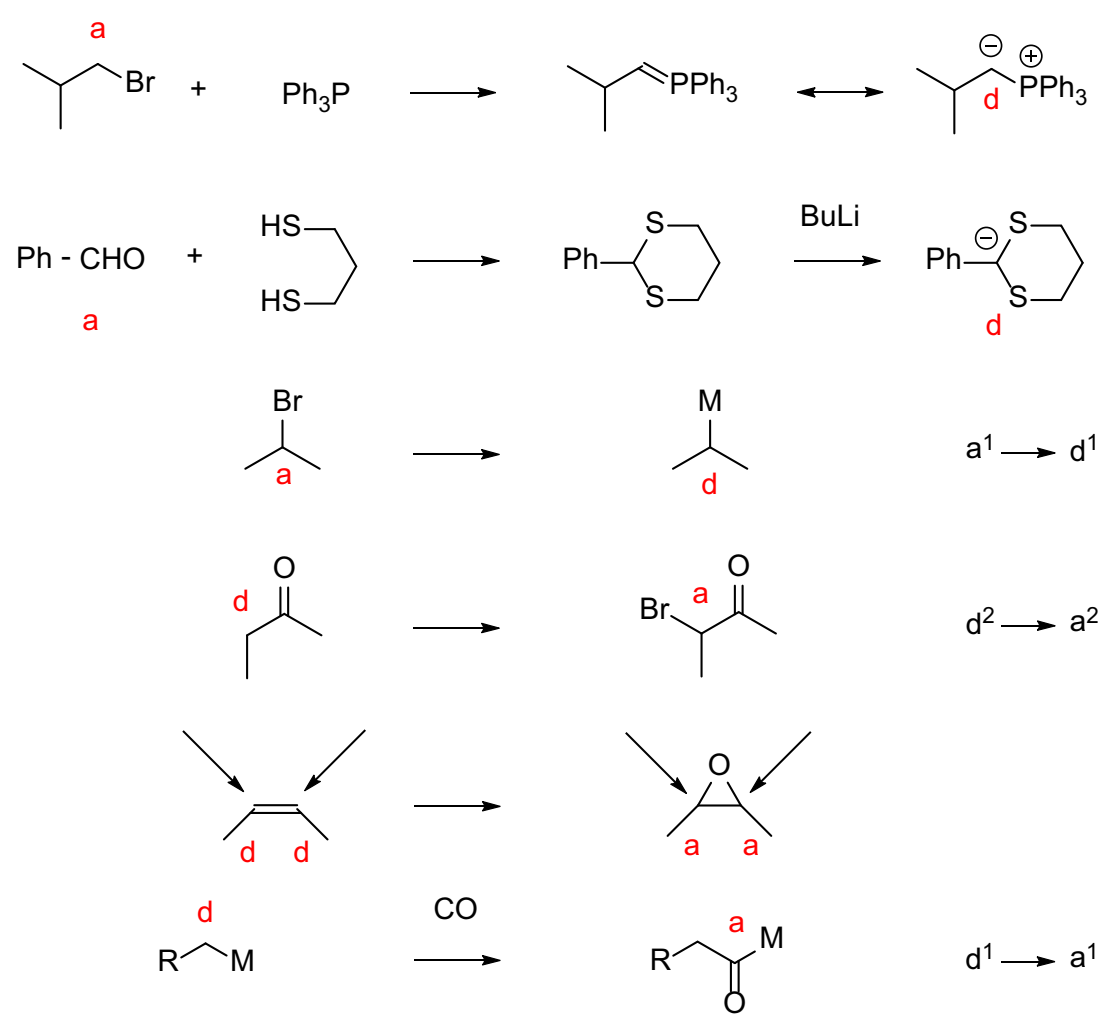


Scheme 11 "Umpolung" by addition of carbon fragments

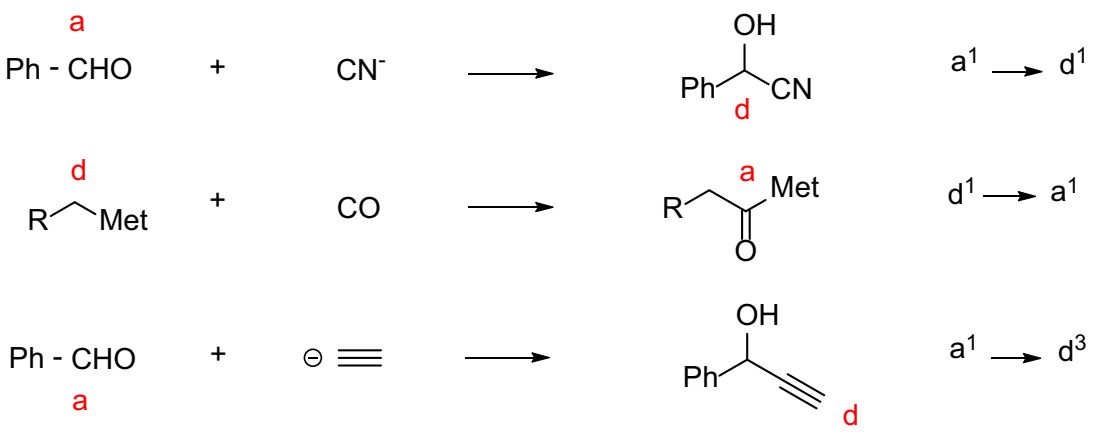

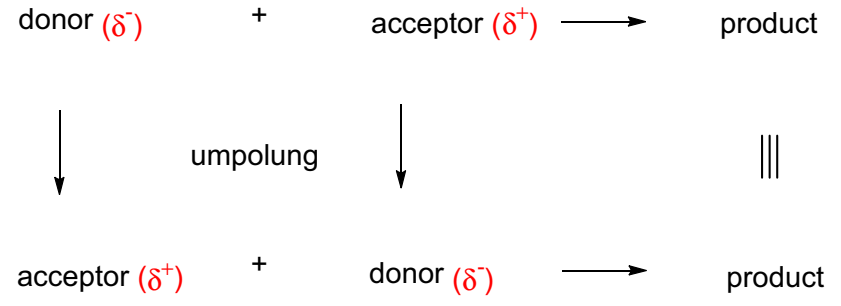

Scheme 12 "Umpolung” strategy

With these tools and methods to hand additional synthetic operations are available to construct a required target molecule. Formally there are four options to synthesize $\beta$ hydroxy ketones (Scheme 16).
By evaluation of these four possibilities to synthesize $\beta$-hydroxy ketones, the $\mathrm{a}^{1}+\mathrm{d}^{2}$ access seems to be the easiest and convenient way-two substrates/one reaction step. But this approach reveals several difficulties. Reaction conditions have to be found to avoid self-aldol additions of reactants and aldol condensation processes (Scheme 17).

To overcome these problems there exist three further alternatives.

$\mathrm{a}^{1}+\mathrm{d}^{2}$ : natural reactivity $\rightarrow 1$ reaction step

$\mathrm{d}^{2}+\mathrm{a}^{1}$ : natural reactivity $\rightarrow 7$ reaction steps

$\mathrm{a}^{2}+\mathrm{d}^{1}$ : "umpoled" reactivity $\rightarrow 4$ reaction steps

$\mathrm{d}^{1}+\mathrm{a}^{2}$ : "umpoled" reactivity $\rightarrow 6$ reaction steps
Scheme 13 Access to $\beta$ hydroxy ketone by "umpolung" reactions

$$
\begin{aligned}
& d^{1}+a^{2} \quad \text { umpoled reactivity } \\
& a^{1}+d^{2} \text { natural reactivity }
\end{aligned}
$$

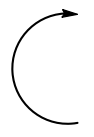<smiles>CCC(O)C(C)C(C)=O</smiles><smiles>C=C</smiles><smiles>CCC=O</smiles><smiles>C#CCC(O)CC</smiles><smiles>C#CCC(=O)Cl</smiles>

$a^{2}+d^{1} \quad$ umpoled reactivity<smiles>CCC(=O)C(C)Br</smiles><smiles>CC1SCCCS1</smiles> 


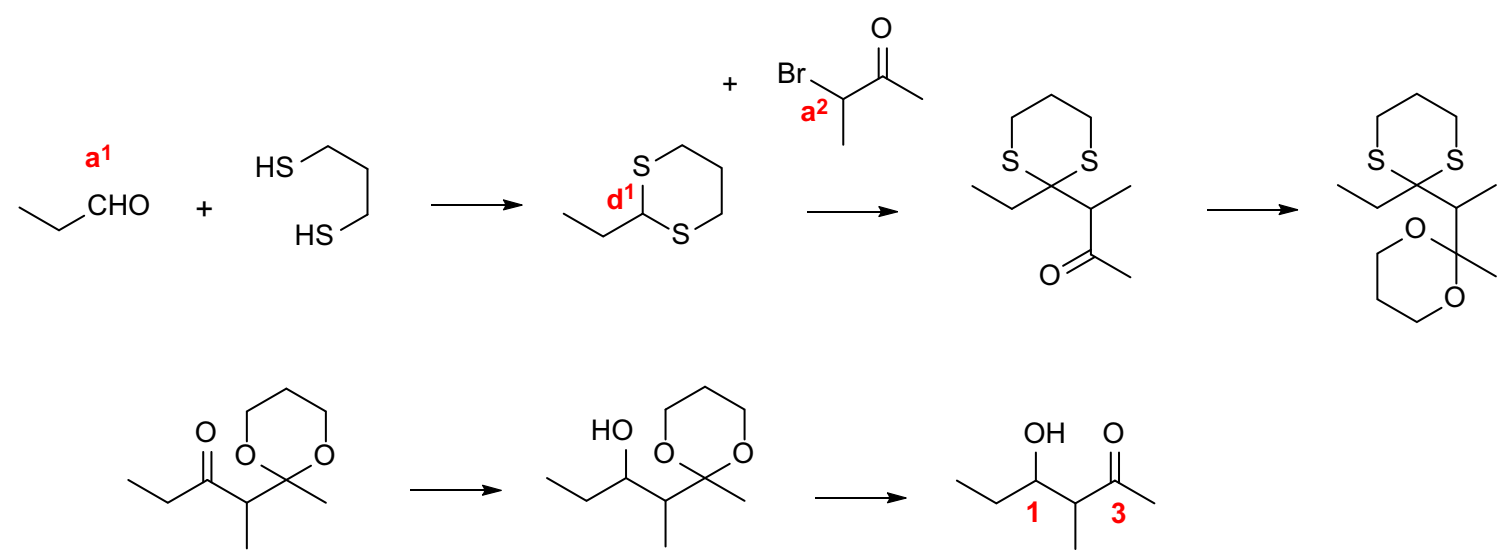

Scheme $14 d^{1}+a^{2}$ Access to $\beta$-hydroxy ketones

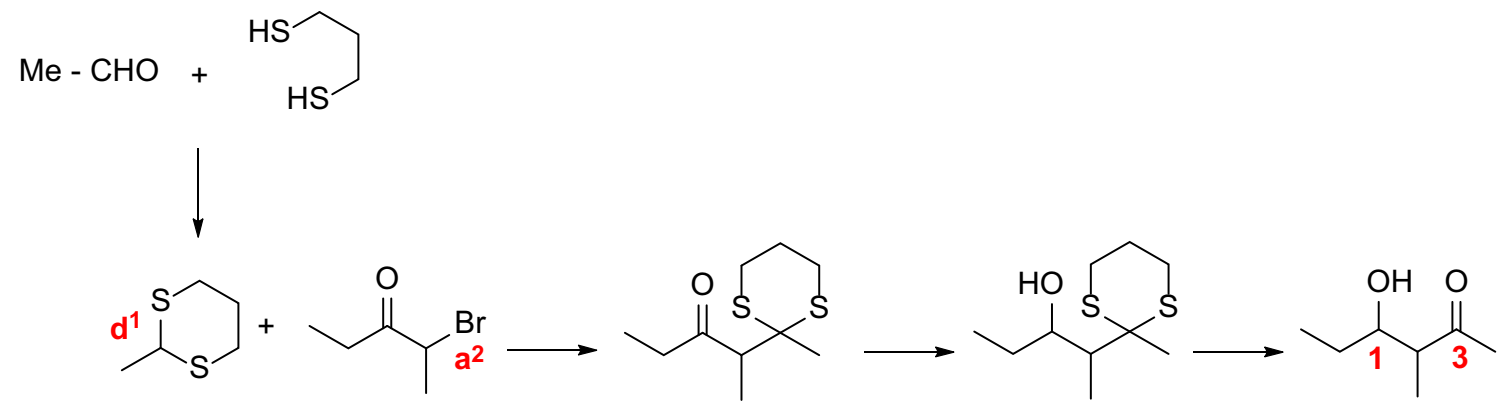

Scheme $15 \mathrm{a}^{2}+\mathrm{d}^{1}$ Approach to $\beta$-hydroxy ketones<smiles>C=C=CC(=O)C(C)=O</smiles>

umpoled reactivity<smiles>CCC(O)C(C)C(C)=O</smiles>

natural reactivity<smiles>CCC(=O)C(C)Br</smiles><smiles>CCC(O)CC</smiles>

$d^{2}+a^{1}$

Scheme 16 Possible operations to synthesize $\beta$-hydroxy ketones

But the guarantee of these additional three ways, to avoid the difficulties discussed for the $\mathrm{a}^{1}+\mathrm{d}^{2}$ access, is bought dearly by further reaction steps, functional group manipulations and application of more reagents. In summary, the higher the distance of the functional groups in the molecule the more alternatives exist. As a result the following theoretical scheme can be developed (Table 1).
A deeper insight reveals that in the "even"-series $(1,2$, $1,4,1,6$ to $1, n)$ one synthon has to be "umpoled" in every reaction under consideration. In this series only synthonpairs with one "umpoled" substrate and one natural substrate are found. These results contrast those of the "odd"series $(1,3,1,5$ to $1, n)$. These reactions can be realized by natural reactivities. But in addition in the odd-series exists 


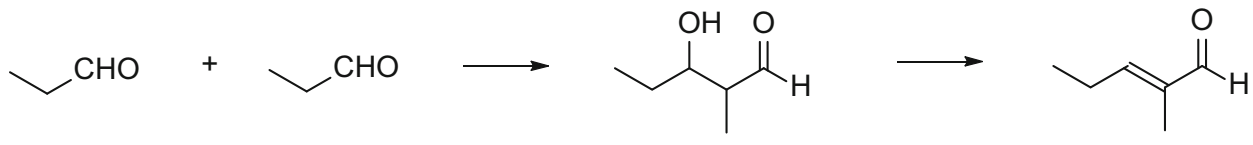

Scheme 17 Self-aldol addition and condensation of the $\mathrm{a}^{1}$ acceptor

Table 1 Retrosynthetic disconnections as a subject to the distances of functional groups

\begin{tabular}{lll}
\hline$n(n \geq 2)$ & $1, n$-Disconnections & Possible disconnections \\
\hline 1,2 & $\mathrm{a}^{1}+\mathrm{d}^{1}$ & $1(2)^{\mathrm{a}}$ \\
1,3 & $\mathrm{a}^{1}+\mathrm{d}^{2}, \mathrm{a}^{2}+\mathrm{d}^{1}$ & $2(4)^{\mathrm{a}}$ \\
1,4 & $\mathrm{a}^{1}+\mathrm{d}^{3}, \mathrm{a}^{2}+\mathrm{d}^{2}, \mathrm{a}^{3}+\mathrm{d}^{1}$ & $3(6)^{\mathrm{a}}$ \\
1,5 & $\mathrm{a}^{1}+\mathrm{d}^{4}, \mathrm{a}^{2}+\mathrm{d}^{3}, \mathrm{a}^{3}+\mathrm{d}^{2}, \mathrm{a}^{4}+\mathrm{d}^{1}$ & $4(8)^{\mathrm{a}}$ \\
$\vdots$ & $\vdots$ & $\vdots$ \\
$1, n$ & $\mathrm{a}^{1}+\mathrm{d}^{n-1} \ldots \mathrm{a}^{n-1}+\mathrm{d}^{1}$ & $n-1[2(n-1)]^{\mathrm{a}}$ \\
\hline
\end{tabular}

a Synthetic possibilities an extra set of corresponding reactions based on "umpoled" substrates.

These considerations demonstrate that a complete and exhaustive retrosynthetic disconnection is the base for a successful synthesis. In the example above there are four alternative reaction paths (the synthesis of $\beta$-hydroxy ketones, 1,3-difunctional compound). A next example, derived from the 1,5-difunctional series, illustrates this greater variety of retrosynthetic disconnections. By analysis of 1,5-diphenylpentanol four possible disconnections can be detected (Scheme 18).

The successful execution of a synthesis depends on a careful and exhaustive retrosynthesis. To this end all possibilities and alternatives should be considered. This statement highlights once more the importance of retrosynthetic exercises.

At the end of such an evaluation process the value of substrates, the availability and costs of reactants and
Scheme 18 Retrosynthetic analysis of 1,5diphenylpentanol

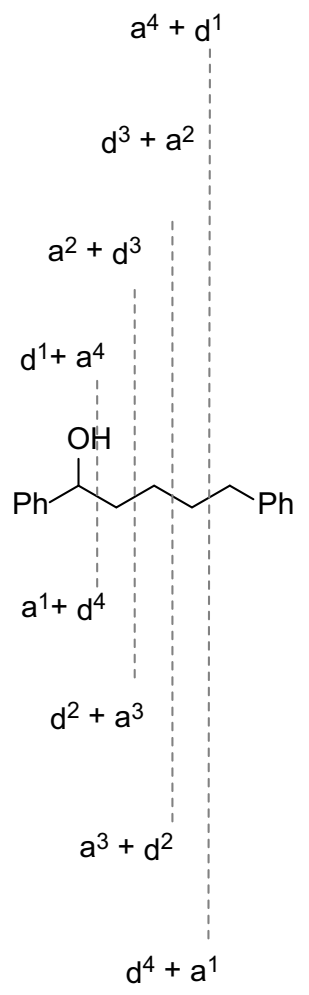

$$
\begin{aligned}
& a^{4}+d^{1} \\
& d^{3}+a^{2} \\
& a^{2}+d^{3} \\
& d^{1}+4^{4}
\end{aligned}
$$<smiles>ClC1C[CH+]CCS1</smiles>

$\mathrm{Br}$ d<smiles>O=C(CCCBr)c1ccccc1</smiles><smiles>O=C(CC[Te](Cl)(Br)Br)c1ccccc1</smiles><smiles>O=C([C]Br)c1ccccc1</smiles>
d a

d<smiles>[OH2+]Cc1ccccc1</smiles><smiles>C[13CH3]</smiles>

$\mathrm{Ph}-\mathrm{CHO}$<smiles>CC(=O)c1ccccc1</smiles><smiles>C=CC(=O)c1ccccc1</smiles><smiles>[18FH]</smiles><smiles>CC(Cl)(CCC[TeH])c1ccccc1</smiles><smiles>O=C(CCC[14C](Cl)Br)c1ccccc1</smiles> 
reagents, the number of reactions steps, the simplicity of purification, etc., determine which way to go.

The length and thus the complexity of a synthesis does not depend on the use of "umpoled" or natural substrates.

These more or less theoretical considerations should be illustrated in the following by systematic analysis of instructive examples.

Configurative or stereochemical aspects are not considered in this text.

Furthermore, we have intentionally avoided extensive discussion of multistep natural product synthesis to strongly focus the reader's attention more strongly on the "logic of organic chemistry".

\section{1,2-Difunctional compounds}

There is only one disconnection and thus in general two synthetic possibilities to synthesize 1,2 difunctional compounds (Table 1). By application of the thesis and laws discussed above, a simple and useful synthesis based on the natural reactivity does not exist. For a 1,2-difunctional compound the following reacting synthon pairs are needed: $a^{1}+d^{1}$ or $d^{1}+a^{1}$. In the natural reactivity series there exists only an $\mathrm{a}^{1}$ acceptor. In contrast, a $\mathrm{d}^{1}$ donator does not exist and we have to prepare the $\mathrm{d}^{1}$ synthon by an "umpolung" reaction (see Schemes 3, 4). An example is given by the synthesis of $\alpha$-hydroxy ketones in Scheme 19 .

Butyraldehyde is naturally reacting as an $\mathrm{a}^{1}$ acceptor. The required donor for this reaction is generated by the transformation of acetaldehyde ( $\mathrm{a}^{1}$ synthon) into the dithiane ( $\mathrm{d}^{1}$ synthon). Subsequent 1,2-addition and deprotection yield $\alpha$-hydroxy-2-hexanone (1,2-difunctional compound) [8].

By changing the reactivity butyraldehyde is transformed into a d ${ }^{1}$ donor (Scheme 20). This is realized by formation of the corresponding dithiane. Subsequent 1,2-addition to acetaldehyde ends up with a 1,2-difunctional compound, however with inverted oxidation states. As a result of that, seven additional reaction steps are necessary to obtain the same $\alpha$-hydroxy ketone as that of the $\mathrm{a}^{1} / \mathrm{d}^{1}$ series (Scheme 19). These reaction steps are characterized by an extensive use of orthogonal protective groups.

This instructive comparison of very simple substrates reveals the requirement and importance of a comprehensive and careful retrosynthetic analysis of a target molecule to successfully develop the corresponding synthesis.

The inorganic equivalent of dithiane donors represents "unmasked" acyl complexes. The acyl-metal complexes are important reactive intermediates. Several acyl metal complexes have been tested for their usefulness. The acylzirconocene complexes turned out to be the most efficient ones in these $\mathrm{C}-\mathrm{C}$ bond formation processes. Acylzirconocene chloride acts as a $\mathrm{d}^{1}$ donor in reactions with aldehydes or imines. Aldehydes or imines are the corresponding acceptors. Again, the result is a 1,2-difunctional compound ( $\alpha$ hydroxy or $\alpha$-amino ketone, Scheme 21).

Besides these transformations, 1,2-difunctional compounds are accessible by several metal-catalyzed methods
Scheme $19 \mathrm{a}^{1} / \mathrm{d}^{1}$ Access to 1,2-difunctional compounds

Scheme $20 \mathrm{~d}^{1} / \mathrm{a}^{1}$ Access to 1,2-difunctional compounds
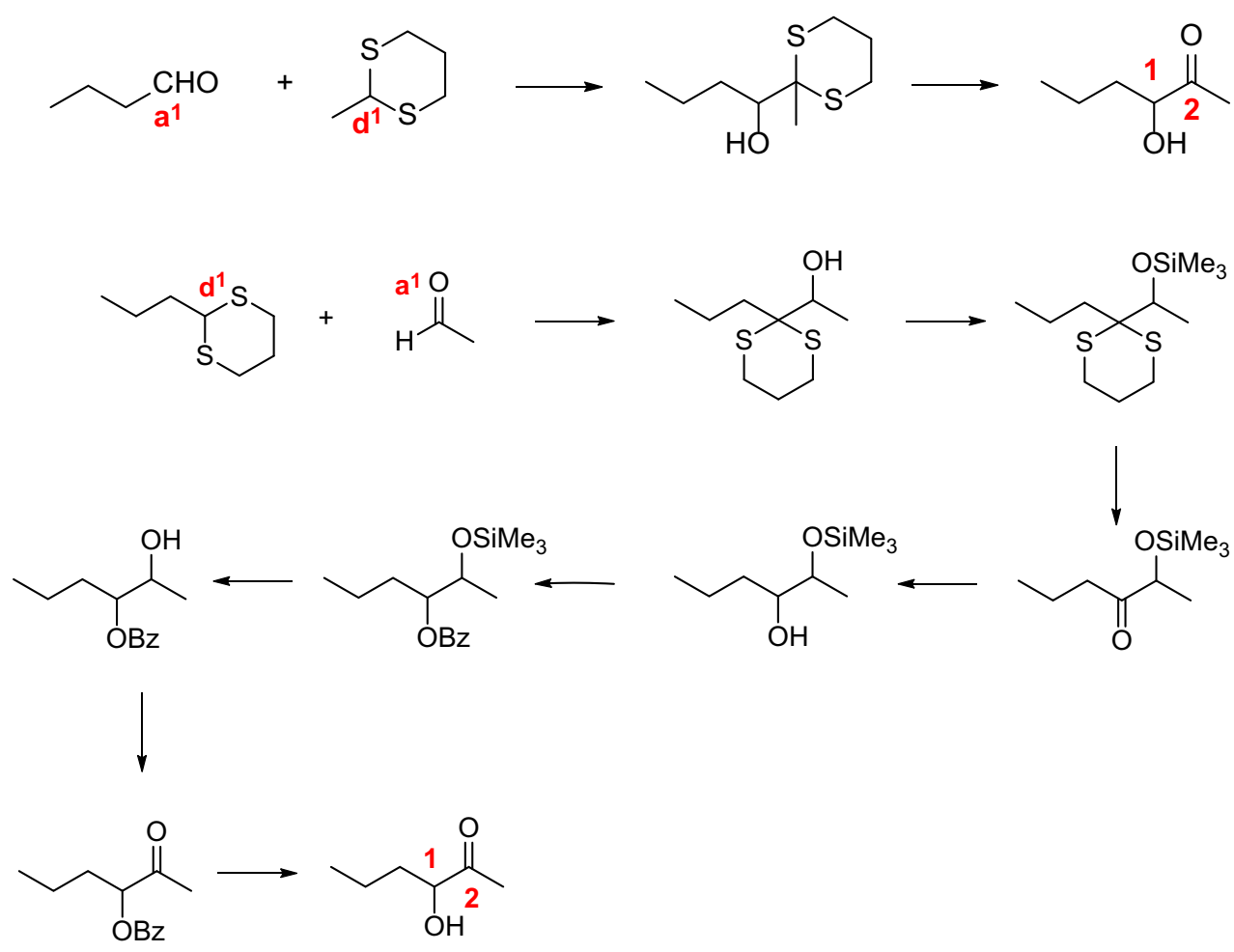
to functionalize carbon-carbon multiple bonds. These are examples of functional group interconversions (FGI).

Methyl ketones are accessible by mercury-catalyzed hydration of terminal alkynes. 1,2-Addition of acetylene to aldehydes yields propargylic alcohols. Subsequent hydration gives an access to $\alpha$-hydroxy methyl ketones. Due to the high regioselectivity of hydration of a 1,2- or a 1,3difunctional compound (propargylic alcohol) only a 1,2difunctional compound is obtained [9] (logical convergence, Scheme 22).

At this point a following small proviso should be noted. The involvement of carbon-carbon multiple bonds into this logical system causes some difficulties. Propargylic alcohols represent a difunctional system. But based on the two carbon atoms, which are involved in the multiple bond we

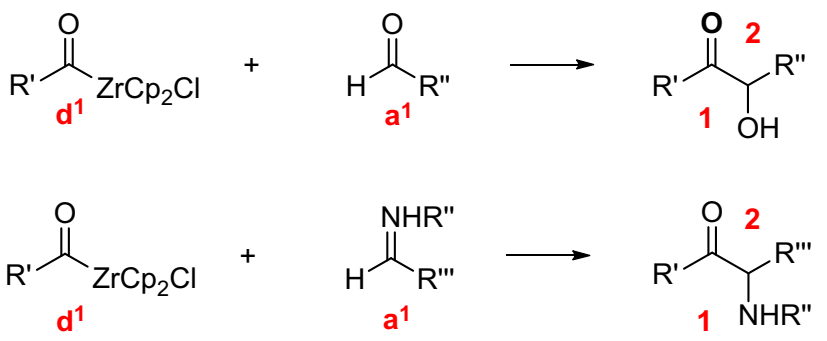

Scheme 21 1,2-Difunctional compounds by reactions with acylzirconocene complexes

Scheme 22 Hydration of terminal propargylic alcohols have to consider a 1,2-difunctional and additionally a 1,3difunctional compound. This difference is visualized by the hydration of propargylic alcohols in the presence of gold(I)-catalyst, which resulted in a $\alpha$-hydroxy ketone $(1,2-$ difunctional compound) (Markovnikov) [10]. This result contrasts those obtained by hydration in the presence of ruthenium(II)-catalyst, which yields the $\beta$-hydroxy aldehyde (1,3-difunctional compound) (anti-Markovnikov) [11]. This high chemoselectivity is demonstrated in Scheme 23.

Based on these considerations an interesting case is depicted in Scheme 24. 1,2-Addition of acetylene to acetaldehyde gives an access to 3-hexin-2,5-diol. Subsequent mercury-catalyzed hydration of the internal triple bond yields a keto-1,4-diol. This compound represents at least a 1,2-, a 1,3- and a 1,4-difunctional compound [12].

Also, the Wacker process provides access to $\alpha$-hydroxy methyl ketones. When used with terminal allylic alcohol (hexen-3-ol) 3-hydroxy hexanon-2 was obtained in this palladium(II)-catalyzed oxidation process. This transformation is depicted in Scheme 25.

To complete this scenario, in contrast to this palladiumcatalyzed oxidation of olefins, 1,3-functional diols were observed by hydroboration [13]. Based on another mechanism, 1,3-difunctional compounds were obtained when used with the same functional substrate (terminal allylic alcohol) in hydroboration (Scheme 26).<smiles>C#C[C-](O)CCCCCC#CC#CC</smiles>

Scheme 23 Hydration of propargylic alcohols

Scheme 24 Hydration of internal propargylic alcohols

Scheme 25 Wacker oxidation to 1,2-difunctional compounds

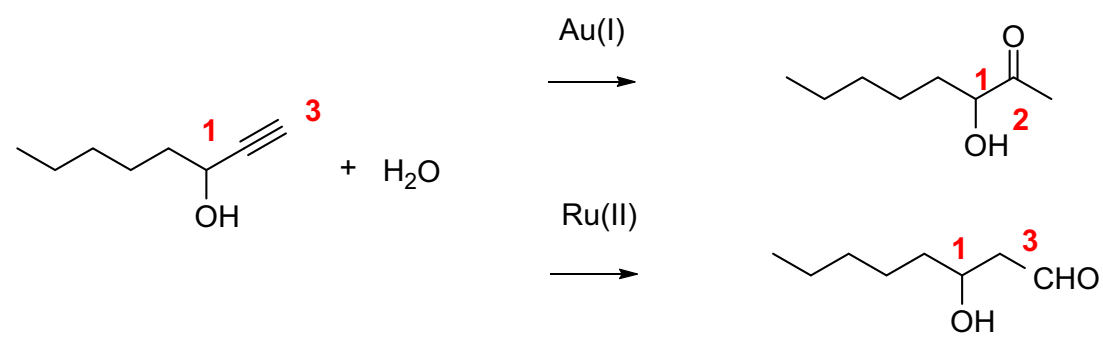

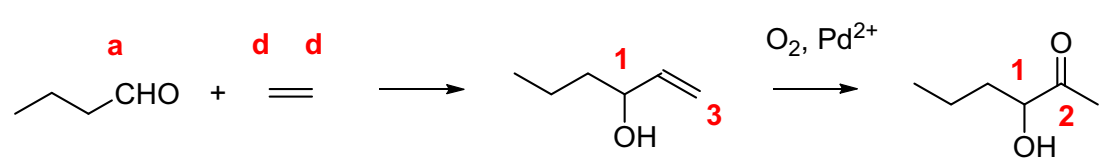


Scheme 26 Hydroboration of allylic alcohol

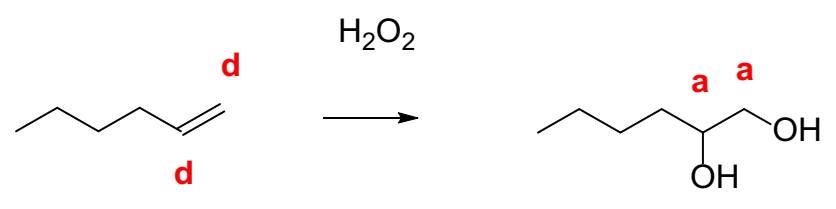

Scheme 27 Dihydroxylation of terminal alkenes

Also the simple oxidation of olefins gives an access to 1,2difunctional compounds. A carbon-carbon double bond reacts as a double donor. Subsequent oxygen gives an access to 1,2-diols (1,2-difunctional compounds) (Scheme 27).

Also, 1,2-diamino compounds can be accessed by palladium-catalyzed amination of terminal olefins [14] (Scheme 28).

One of the most important classes of 1,2-difunctional pattern represents the class of $\alpha$-amino acids. Retrosynthetic considerations indicate a simple carboxylation of an amine as a solution of this synthetic problem. This retrosynthetic path we recognize from biochemistry as the decarboxylation of amino acids. This is the natural source for biogenic amines (Scheme 29).

The reversed process, the direct carboxylation of primary amines, should be a reaction of two acceptors. For reasons of polarity this process is unknown so far. A realization for this 1,2-connection is given by the "umpolung" of one of the reactants. The synthetic solution of this problem is the addition of cyanide to a carbonyl function $\left(\mathrm{CN}^{-}\right.$as the synthetic equivalent for $\left.\mathrm{CO}_{2}\right)$. This reaction is widely used and named Strecker reaction (Scheme 30).

By a multicomponent reaction, a corresponding aldehyde is reacted with ammonium chloride and potassium cyanide in the presence of acids. Subsequent hydrolysis of the obtained $\alpha$-amino nitrile gives an access to $\alpha$-amino acids. Thus, by the use of acetaldehyde alanine can be obtained (R: Me, Scheme 31).

Once more, the addition of cyanide to an aldehyde, as this is depicted in Scheme 31 for the Strecker reaction, is not an artificial transformation. This reaction is found even in nature. Cyanogenic glycosides are an important group of

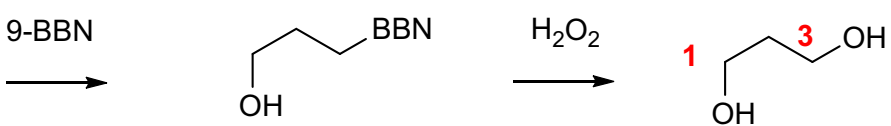<smiles>[R]C=C[C+](N)C(=O)O</smiles>

Scheme 29 Retrosynthetic disconnection of $\alpha$-amino acids

mainly plant-derived materials, which liberate hydrogen cyanide by injuries. Thus they act as natural toxicants (amygdalin, prunasin, dhurrin, linamarin, lotaustralin, etc.). These substances (1,2-dunctionalized compounds) are found in stones of almonds, apricots, cherries, peaches, beans, plums, etc. (Scheme 32).

The reaction of aldehydes with cyanides is also used for chain elongation of carbohydrates, the so-called KilianiFischer synthesis. The open acyclic structure of mannose reacts with cyanide to give the expected cyanohydrin. Subsequent hydrolysis yields the $\mathrm{C} 1$-elongated aldonic acid (Scheme 33) [15].

Also, the deployment of acyl anion synthons in $\mathrm{C}-\mathrm{C}$ bond formation processes represents a useful tool for the synthesis of 1,2-difunctional compounds. This aim can be realized by the decarboxylative $\mathrm{C}-\mathrm{C}$ bond formation processes of activated ketones ( $\alpha$-keto carboxylic acids) as depicted in Scheme 34.

At first glance, this process looks like an artificial one by polarity. It would appear to be a formal $\mathrm{C}-\mathrm{C}$ bond formation between two acceptors, which would never work by polarity control. But far from it, this reaction is widely used by Nature in carbohydrate chemistry. By deployment of hydroxypyruvate in reactions with aldehydes (glyceraldehyde) defined configured carbohydrates can be constructed. These reactions are catalyzed by transketolases. On further analyzing a hydroxymalonate semialdehyde can be drawn as the required donor. By this tautomerism a formal "umpolung" is realized and the addition of glyceraldehyde proceeds smoothly now by base-catalysis (Scheme 35).

A further example of 1,2-difunctional compounds in carbohydrate chemistry represents the enzymatic synthesis of 1-deoxy-xylulose. The coenzyme thiamine diphosphate catalyzes the decarboxylative reaction of pyruvic acid with
Scheme 28 Palladiumcatalyzed amination of terminal olefins

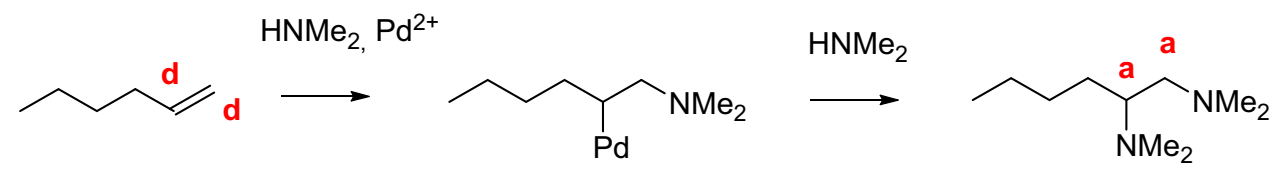


Scheme 30 Retrosynthesis of $\alpha$-amino acids

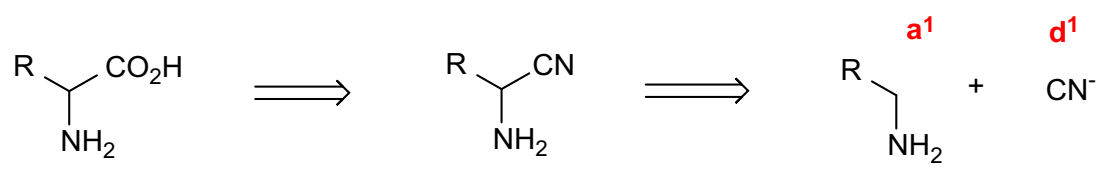

Scheme 31 Synthesis of $\alpha$ amino acids-Strecker reaction

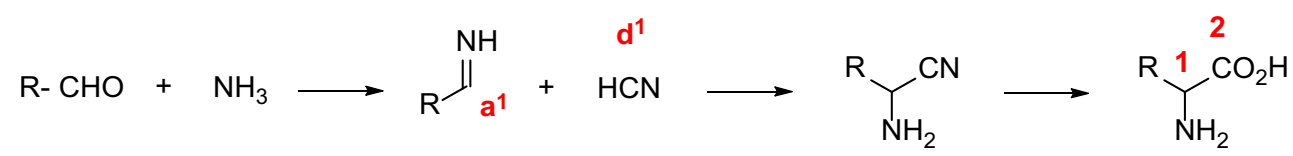

Scheme 32 Retrosynthesis of cyanogenic glycosides<smiles>N#CC(OC1OC(CO)[C@H](O)C(O)[C@H]1O)c1ccccc1</smiles>

prunasin

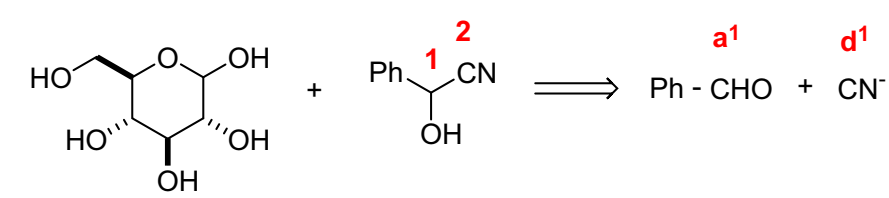

Scheme 33 C1-elongation of carbohydrates

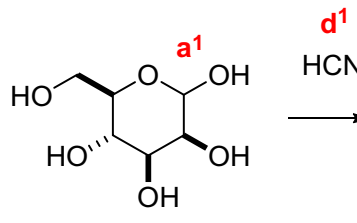<smiles>N#C[C@H](O)[C@@H](O)[C@H](O)[C@H](O)[C@H](O)CO</smiles><smiles>CCOC</smiles><smiles>CC(=O)C(O)[C@H](O)[C@H](O)C(O)C(O)[C@H](O)CO</smiles>

Scheme 34 Decarboxylative $\mathrm{C}-\mathrm{C}$ bond formation<smiles>O=C(O)CO</smiles><smiles>[R]C(=O)C(O)F</smiles><smiles>C=C</smiles><smiles>[R]C=O</smiles>

$\mathrm{OHC}-\mathrm{R}$ $a^{1}$<smiles>O=CO</smiles><smiles>[R]C(O)C(=O)CO</smiles>

glyceraldehyde. Following the reaction path of Scheme 36 a base generates the carbanion (or thiamine ylide) which reacts with pyruvic acid to give the tertiary alcohol. Subsequent decarboxylation gives an access to enamine (donor of acetalydehyde), which reacts with glyceraldehyde to form the corresponding 1-deoxy-ketopentose. The necessary "umpolung" was achieved by a decarboxylation that yields an enamine - the reactive donor for the following reaction with the glyceraldehyde. At that stage an "umpolung" of an acceptor carbon atom to a donor carbon atom is realized. Now a $\mathrm{C}-\mathrm{C}$ bond formation process can proceed based on logical reactivities.

Also, several interesting syntheses of 1,2-difunctional compounds have been reported in the ever growing field of organocatalysis. Enolizable aldehydes can be enantioselectively functionalized in $\alpha$-position. This is realized by the formation of the intermediate enamine of octanal and the chiral imidazolidinone. Subsequent chlorination by the perchlorinated quinone yields $\alpha$-chloro octanal (1,2-difunctional compound) (Eq. 1, Scheme 37) [16].

A further and similar example represents the enantioselective oxidation of enolizable aldehydes. The intermediately formed enamine of propionaldehyde and proline was selectively reacted with nitrosobenzene. The resulting $\alpha$-oxoaldehyde represents again a 1,2-difunctional compound (Eq. 2, Scheme 37) [17].

The last example-the organocatalyzed approach to chiral epoxides_-was realized by an "umpolung" of benzyl 
Scheme 35 Enzyme-catalyzed decarboxylative synthesis of xylulose<smiles>CC=COC(=O)C(O)=CO</smiles><smiles>O=CC(O)C[18O][Na]</smiles>

a

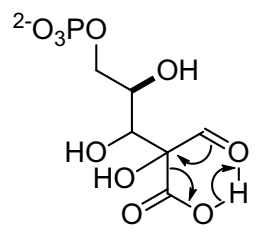<smiles>O=C([O-])CC1CC1</smiles><smiles></smiles><smiles>CCC(O)C(O)/C(O)=C/O</smiles>

Scheme 36 Enzymatic synthesis of 1-deoxy-xylulose (1,2-difunctional compound)

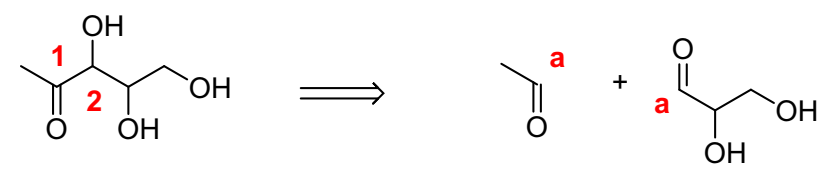

1-deoxy-xylulose

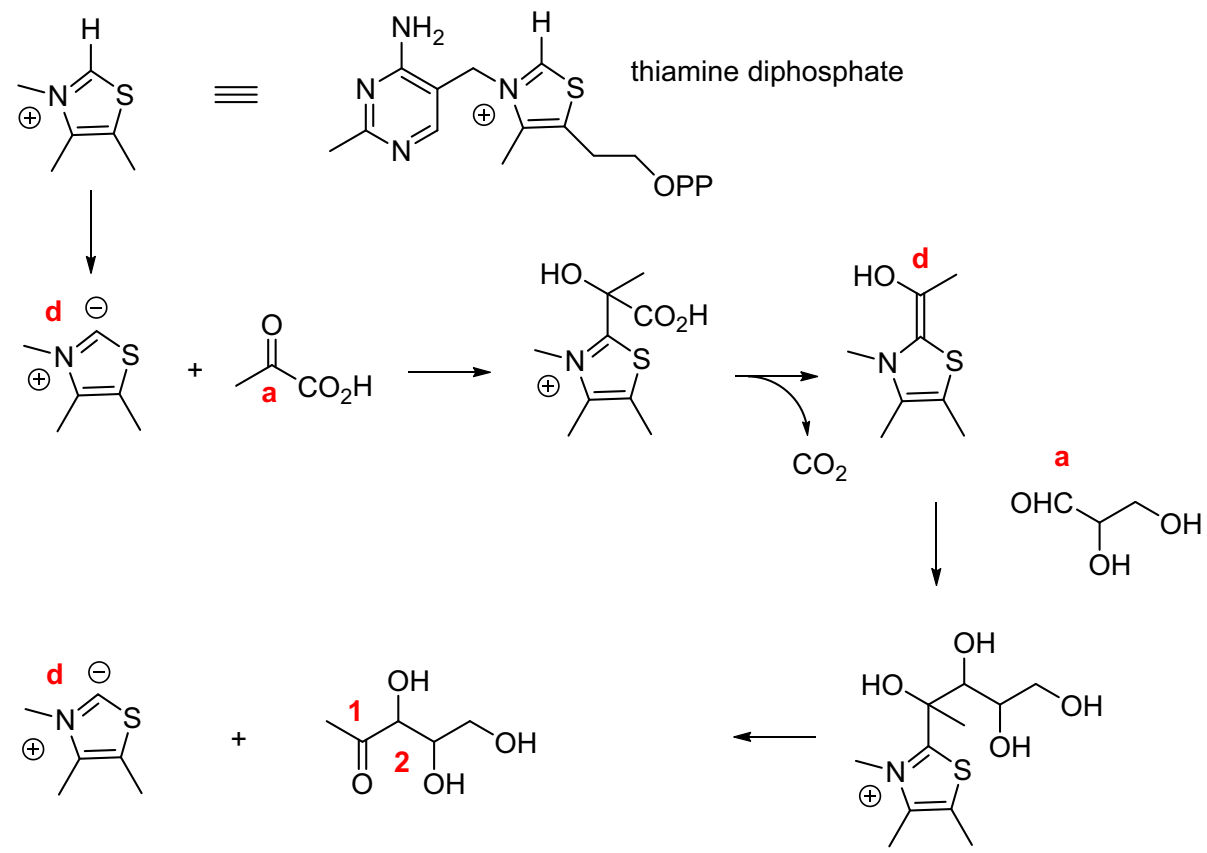

bromide and subsequent reaction with benzaldehyde as the corresponding acceptor. The "umpolung" was achieved by the reaction of benzyl bromide (acceptor) with the chiral sulfide in a basic two-phase system, to give the sulfonium salt (donor) [18]. This reaction can be compared with generation of the phosphonium salt for the Wittig reaction (Eq. 3, Scheme 37).
To complete this discussion it should be mentioned, that beside the discussed $\mathrm{C}-\mathrm{C}$ bond formation processes several powerful methodologies were reported for the synthesis of 1,2-difunctional compounds, which do not follow the donor/acceptor principle as discussed above. Instead they are based on radical bond formation processes. These are pinacol [19] coupling or acyloin coupling [20] reactions as 
Scheme 37 Organocatalytic access to 1,2-difunctional compounds

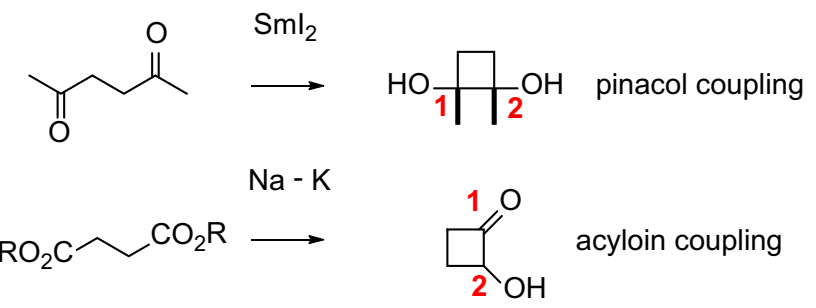

Scheme 38 1,2-Difunctional compounds by reactions of radicals

depicted in Scheme 38. But they are not the focus of this discussion.

\section{1,3-Difunctional compounds}

1,3-Difunctional compounds are important units or intermediates in a great many of the natural products and can be synthesized by natural reactivities. There are two synthetic possibilities of changing of the donor and the acceptor in the following way: $\mathrm{d}^{2}$ and $\mathrm{a}^{1}$ or $\mathrm{a}^{1}$ and $\mathrm{d}^{2}$. By including the "umpoled" reactivities into this series we have four alternative logical routes to synthesize 1,3-difunctional compounds $\left(\mathrm{a}^{2} / \mathrm{d}^{1}\right.$ and $\left.\mathrm{d}^{1} / \mathrm{a}^{2}\right)$. Once more though, this diversity is bought at the cost of additional functional group interconversions (FGI) and/

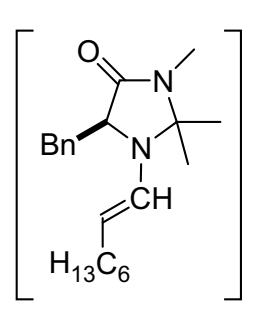<smiles>CC(Cl)C(C)C=O</smiles>

$71 \%, 92 \%$ ee<smiles>CCCCC1CCCN1CC</smiles>

$$
88 \%, 97 \% \text { ee }
$$

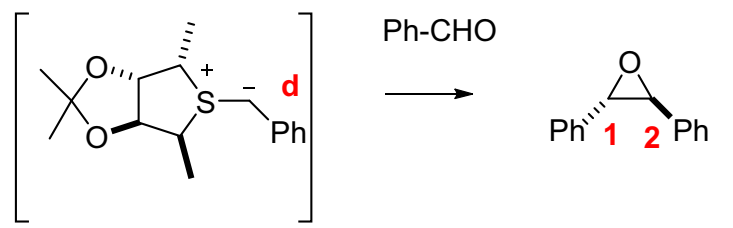

$88 \%$, trans/cis: $83 / 17$ $98 \%$ ee or an extensive handling of protective groups. This is discussed in Scheme 16 for retrosynthetic analysis of aldol addition.

A formal and full retrosynthetic analysis of 1,3-difundtionalized compounds is depicted in Scheme 39. There are two routes in the natural series $\left(\mathrm{d}^{2} / \mathrm{a}^{1}\right.$ and $\left.\mathrm{a}^{1} / \mathrm{d}^{2}\right)$ and two additional routes in the "umpoled" run $\left(\mathrm{a}^{2} / \mathrm{d}^{1}\right.$ and $\left.\mathrm{d}^{1} / \mathrm{a}^{2}\right)$.

These retrosynthetic considerations resulted in the following synthetic plans. $\beta$-Keto esters can easily be prepared by reactions of acylhalogenides and ketones in the presence of metalorganic bases (LDA, LiHMDS, etc.). This transformation poses not a challenge and the reaction proceeds without any problems (Scheme 40) [21].

Also, reactions of acyl halogenides with esters were reported. They were carried out in the presence of lithium $N$-isopropylcyclohexylamide (LiICA) to give the expected $\beta$-keto esters in high yields (Scheme 41) [22].

In addition, by incorporation of carbon-carbon multiple bonds into this logical system, an access to 1,3-difunctional compounds is given by the 1,2-addition of metalated multiple bond to carbonyl compounds. An interesting example is the reaction of methyl tert-butyl ketone with acetylene in the presence of tetrabutylammonium hydroxide to give the tertiary alcohol (Scheme 42) [23]. Again this is a name reaction-the Favorskii reaction. 
Scheme 39 Retrosynthetic disconnection of 1,3difunctional compounds<smiles>CCC(=O)C=C(C)C(=O)O</smiles><smiles>C=C</smiles><smiles>CCC(=O)O</smiles>

$+$ $\mathrm{ClCO}_{2} \mathrm{Et}$ $a^{1}$<smiles>CCC(=O)CBr</smiles><smiles>CCOC(=O)CC(=O)CC</smiles><smiles>CCC(=O)Cl</smiles>

$+$<smiles>CCOC(C)=O</smiles>

$\mathrm{d}^{2}$<smiles>CCOC(=O)CBr</smiles><smiles>CCOC(=O)CC(C)C(=O)OCC</smiles>

Scheme $40 \mathrm{~d}^{2} / \mathrm{a}^{1}$ Access to 1,3-difunctional compounds<smiles>CCC(=O)CC(=O)CC</smiles>

Scheme $41 \mathrm{a}^{1} / \mathrm{d}^{2}$ Access to 1,3-difunctional compounds<smiles>C=CC1(O)CCCCC1</smiles><smiles>C#CC(C)(O)C(C)(C)C(C)(C)O</smiles>

Scheme 42 1,2-Addition of multiple C-C bonds to carbonyl functionalities

Reaction of 1-bromo-2-butanone ( $\mathrm{a}^{2}$ acceptor) with dithiane of formaldehyde ( $\mathrm{d}^{1}$ donor) should provide an access to $\beta$-keto ester via the application of "umpoled" reactivities (Scheme 43). To avoid problems with the keto group the $\mathrm{C}-\mathrm{C}$ bond formation process should be carried out with a cuprate of butyl lithium [24]. Subsequent deprotection, oxidation and esterification yield the expected $\beta$-keto ester (1,3-difunctional compound).

The other unnatural route $\left(\mathrm{d}^{1} / \mathrm{a}^{2}\right)$ works with the "umpoled" propionaldehyde. The following $\mathrm{C}-\mathrm{C}$ bond formation process with ethyl bromoacetate proceeds smoothly in the presence of butyl lithium. Subsequent deprotection yields the expected $\beta$-keto ester (Scheme 44).

The advantage of reactions leveraging natural reactivity is quite clearly demonstrated by comparing these four approaches to $\beta$-keto ester. Only one simple reaction is necessary to build $\beta$-keto ester via the natural route (Scheme 40). In the unnatural series protected "umpoled" reactants have to be synthesized and deprotected. In the reaction of dithiane of formaldehyde additional oxidation and esterification have to be carried out.

Besides these formal examinations to synthesize 1,3difunctional compounds exist a great number of reactions to form 1,3-difunctional patterns.

1,3-Difunctional patterns are wide-spread in nature, in the synthesis of polyketides and fatty acids. They were synthesized by classical and prominent reactions as they are aldol additions, Mannich reactions or ester condensations.

The retrosynthetic examinations of aldol reactions have been done in Schemes 14, 15 and 16. Due to the importance of this reaction in total syntheses of natural products a plethora of methods have been elaborated. Some important and classical methodologies to synthesize aldol adducts are depicted in Scheme 45.

The cross aldol condensation of a ketone and nonenolizable aldehyde is called Claisen-Schmidt condensation. A typical example is the reaction of benzaldehyde and acetone. The incorporation of the double bond into the 


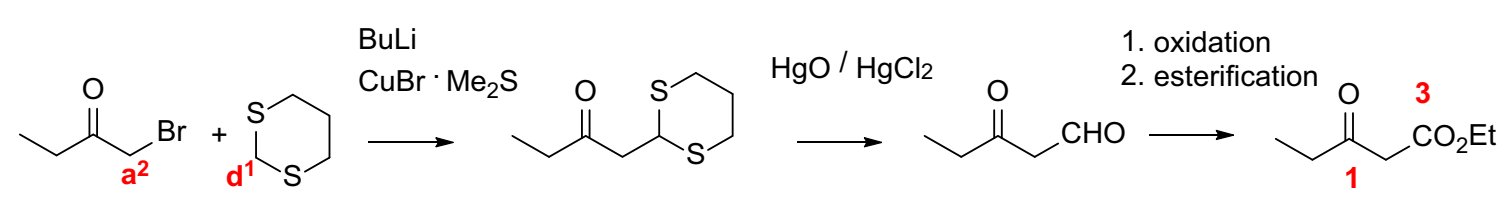

Scheme $43 \mathrm{a}^{2} / \mathrm{d}^{1}$ Access to 1,3-difunctional compounds

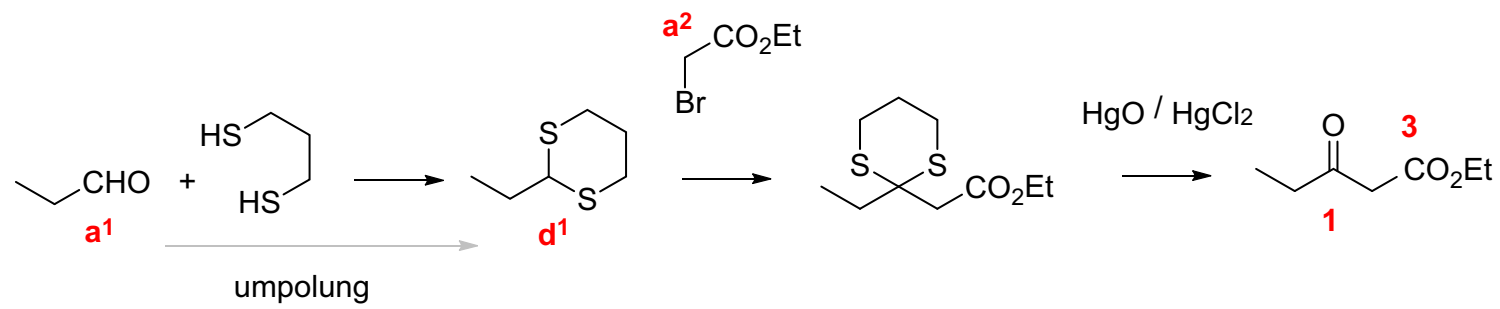

Scheme $44 \mathrm{~d}^{1} / \mathrm{a}^{2}$ Access to 1,3-difunctional compounds

Scheme 45 1,3-Difunctional compounds by aldol reactions

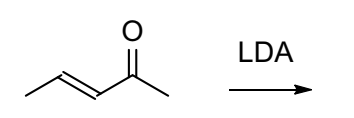<smiles>C=C(Cl)C=CC</smiles><smiles>CC=CC=O</smiles><smiles>CC=CC(=O)CC(O)C=CC</smiles><smiles>CCC(=O)C(C)(C)C</smiles>

1. $\mathrm{R}_{2} \mathrm{BOTf}$
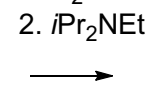<smiles>[R10]OC(=CC)C(C)(C)C</smiles><smiles>[C+][C+]</smiles>

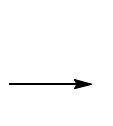<smiles>CC(C(=O)C(C)(C)C)C(O)c1ccccc1</smiles><smiles>O=C1CCCC1</smiles><smiles>OC1=CCCC1</smiles><smiles>[CH+][PbH]C=O</smiles>

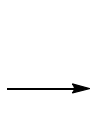<smiles>O=C1CCCC1C(O)c1ccccc1</smiles>

TMSO<smiles>COC1=CCCC1</smiles><smiles>O=C1CCCC1</smiles>
1. cat. $\mathrm{TiCl}_{4}$

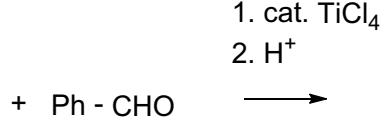<smiles>O=C1CCCC1C(O)c1ccccc1</smiles>

$+\mathrm{Ph}-\mathrm{CHO}$<smiles>O=C1CCC[C@H]1C(O)c1ccccc1</smiles>

considerations of logic identifies benzalacetone as a 1,3difunctional compound (Scheme 46).

A well-known and at the same time interesting example in the aldol series is found in the synthesis of the Wieland-Miescher or Hajos-Parrish ketone. For the application of these important intermediates in total synthesis of natural products see Ref. [25]. By retrosynthetic examinations 1,5- and 1,3-difunctional situations were identified. Independent of the starting cyclic 1,3-diketone (cyclohexanedione or cyclopentanedione) the same reaction should give an access to the annulated cyclohexenones based on natural reactivities. This is achieved via a carba-Michael/aldol cascade reaction of methyl vinyl ketone with methyl-1,3-cyclohexanedione or methyl-1,3-cyclopentanedione. A 1,3-difunctional compound-the cyclic $\beta$-hydroxy ketone-is obtained. This aldol adduct undergoes a subsequent dehydration to give the cyclic $\alpha, \beta$-unsaturated ketone-a 1,3-difunctional compound. This reaction sequence is an important transformation and called the Robinson annulation. A current example is found in the total synthesis of cortistatin A (Scheme 47) [26]. 
Furthermore, the nitrogen analogs of aldol adducts- the $\beta$-amino ketones-represent 1,3-difunctional compounds by retrosynthetic considerations. Again, based on the discussed logic, there has to exist an easy access to this class of compounds, guided by natural reactivities. This is the so-called Mannich reaction, which can be carried out with preformed imines and the corresponding carbonyl

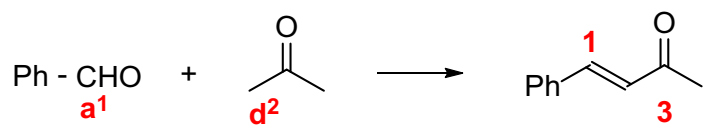

Scheme 46 Aldol condensation of benzaldehyde and acetone (Claisen-Schmidt condensation) component or as a reaction of all three components (multicomponent reaction). Thus, by reaction of cyclohexanone, benzaldehyde and pyrrolidine the Mannich product-a 1,3difunctional compound-is accessible in high yields (Scheme 48) [27].

An illustrative example for this transformation is the elegant biomimetic synthesis of tropinone by Robinson [28]. By reaction of succinaldehyde with methylamine a cyclic hemiaminal is formed. Subsequent decarboxylative Mannich reaction with acetone dicarboxylic acid yields tropinone (Scheme 49).

When used with the monomethyl ester of acetone dicarboxylic acid an operationally simple access to cocaine is given (Scheme 49) [29].<smiles></smiles><smiles>C=CC(C)=O</smiles>

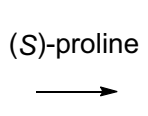<smiles>[CH]C(=O)CC[C@@]1(C)C(=O)CCC1C</smiles><smiles></smiles><smiles>CC12CC=C3C=C4[C@@H](O)C(O)[C@@H](N)C[C@]45CC[C@]3(O5)[C@@H]1CC[C@H]2c1ccc2ccncc2c1</smiles>

$(+)$-cortistatin A

Scheme 47 1,3-Difunctional compounds

Scheme $48 \beta$-Amino ketone by Mannich reaction

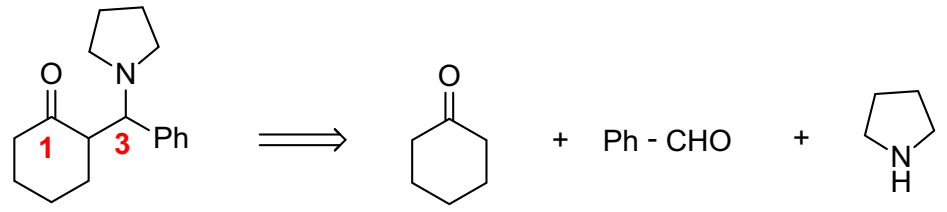<smiles>CCN(CC)C(c1ccccc1)C1CCCCC1=O</smiles> 

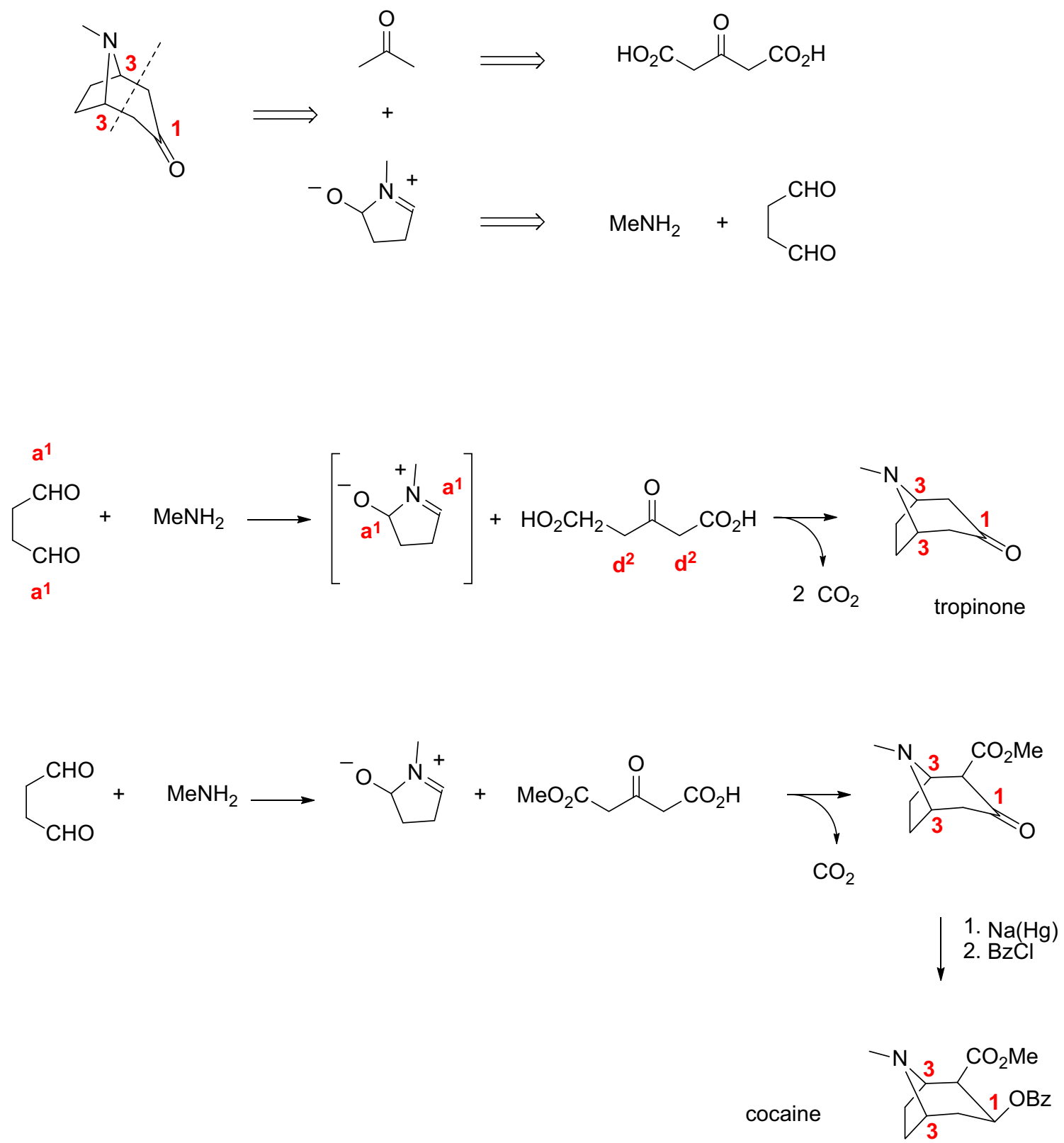

Scheme 49 Robinson synthesis of tropinone and cocaine

A similar 1,3-difunctionalization ( $\beta$-amino ketone) is given by the so-called aza-Baylis-Hillman reaction [30]. Retrosynthetic analysis of these compounds suggests the reaction of an imine with the corresponding $\alpha, \beta$-unsaturated ester. Indeed by amine- or phosphine-catalyzed reaction the corresponding $\beta$-amino esters can be obtained (Scheme 50). In contrast, the 3-position of acrylic esters can be accessed by a Michael addition, but this is the subject of 1,4-difunctional compounds.

If identical esters can be applied, ester condensations are a useful tool to access 1,3-difunctional compounds. There are a great many different protocols of ester condensation processes and all are connected with great names.
The Dieckmann condensation is an intramolecular Claisen condensation. The Knoevenagel condensation is a special case of aldol condensation. Also, the KnoevenagelDoebner reaction is a special case of the aldol condensation. In these reactions the free malonic acid is used as substrate (Scheme 51).

Also 1,4-difunctional substrates are used in ester condensation processes. Based on the logic the synthetic transformation represents a 1,3-difunctional compound. But the original 1,4-difunctionalization of substrate (succinic acid) is conserved (Scheme 52).

When different carbonyl compounds (esters) are used in these transformations complicated mixtures of products are 
<smiles></smiles>

3<smiles>C=CC(=O)OC(C)C</smiles>

Scheme $50 \beta$-Amino ester by aza-Baylis-Hillman reaction ( $\mathrm{Ns}=$ nitrobenzenesulfonyl)

Scheme 51 1,3-Difunctional compound by ester condensations

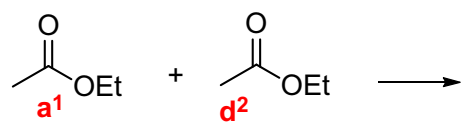<smiles>CCOC(=O)CC(C)=O</smiles>

Claisen condensation<smiles>CCOC(=O)CCCCCC(=O)OCC</smiles><smiles>CCOC(=O)C1CCCC1=O</smiles>

Dieckmann condensation<smiles>CCOC(=O)CC(=O)[O-]</smiles><smiles>CC(=O)[18F]</smiles>

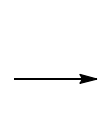<smiles>CCOC(=O)C(C(=O)OCC)=C(C)C</smiles>

Knoevenagel<smiles>CC(C)[C@@H](C(=O)O)C(=O)O[Na]</smiles><smiles>O=C(O)/C=C/c1ccccc1</smiles>

Knoevenagel-Doebner
Scheme 52 Stobbe condensation<smiles>CCOC(=O)CCC(=O)OCC</smiles><smiles>CCOC(I)C1CC(=O)OC1(c1ccccc1)c1ccccc1</smiles>

formed. An interesting synthetic solution of this problem can be found within this context by the Reformatsky reaction [31, 32]. As pointed out in Scheme 39, a synthetic access to 1,3-difunctional compounds is also given by the deployment of "umpoled" substrates. This is realized by the Reformatsky reaction of ethyl bromoacetate with zinc to generate the carbanion ("umpolung" of an $\mathrm{a}^{2}$ acceptor into a $\mathrm{d}^{2}$ donor). The reaction is carried out with zinc to avoid problems with the ester functionality (1,2-addition, etc.). Subsequent reaction with propionylchloride yields the desired $\beta$-keto ester, which contains an acetate fragment and a propionate fragment (Scheme 53). Such a carbon backbone is not clearly accessible with high yields by the ester condensations described above (Scheme 51).

A typical example for the inflationary use of name reactions is the Hell-Volhard-Zelinsky/Reformatsky 
Scheme 53 1,3-Difunctional compounds by Reformatsky reaction

$$
\text { propionate acetate }
$$<smiles>C=CCC(=O)CC(C)=O</smiles><smiles>CCOC(=O)CCCC(=O)CC(=O)OCC</smiles>

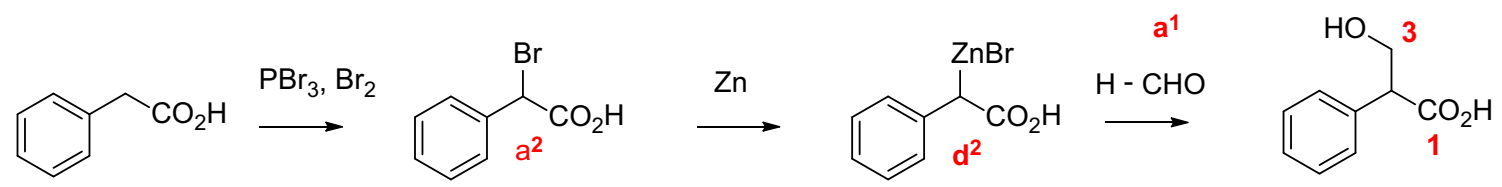

Scheme 54 1,3-Difunctional compounds by Hell-Volhard-Zelinsky/Reformatsky reaction

sequence leading to 1,3-difunctional compounds. The required "umpolung" is achieved by the formation of the zinc intermediate (Scheme 54).

All these discussed reactions are key steps and are widely used in the synthesis of important classes of compounds in Nature. This holds true for both, compounds of primary and secondary metabolism in which we will demonstrate that by several important transformations.

The first step of the citric acid cycle is a simple aldol addition of acetyl-CoA with oxaloacetate. As a result of that the symmetric tertiary alcohol—citric acid—is formed (Scheme 55).

Similarly, the first step of the fatty acid synthesis is a decarboxylative Claisen reaction of acetyl-CoA and malonyl-
CoA and leads to a 1,3-difunctional compound. This important metabolic step is based on natural reactivities and is supported by the formation of carbon dioxide (Scheme 56).

By iterative utilization of this methodology poly- $\beta$-keto esters are accessible. Driving force for this transformation is the formation of carbon dioxide (Scheme 57).

Subsequent aldol condensation of poly- $\beta$-keto esters gives an access to aromatic polyketide compounds, which is demonstrated in the synthesis of phloracetophenone (Scheme 58).

On this stage, the tracks of the logic of enzymatic transformation to phloracetophenone are covered up. Nobody would synthesize phloracetophenone by this enzymatic pathway. The simple synthetic solution is the<smiles>O=C(O)CC(=O)[CH]C(=O)O[Na]</smiles>

Scheme 55 Aldol reaction of acetyl-CoA with oxaloacetate. Starting sequence of the citric acid cycle

Scheme 56 Formation of acetoacetyl-CoA. Starting sequence of the $\beta$-oxidation of fatty acids<smiles>O=C(O)CC(=O)SOC(=O)[O-]</smiles>

malonyl-CoA<smiles>CC(=O)SC(=O)O</smiles>
acetyl-CoA<smiles>[3H][C@H]1C[13CH]1C</smiles><smiles>CC(=O)CC(=O)[Se]O</smiles>

CoA-SH 


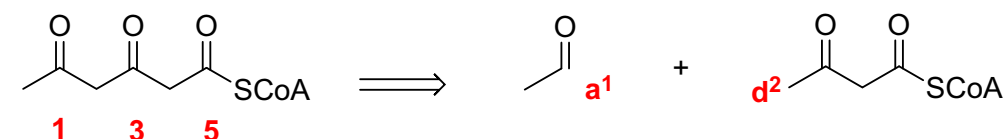

13<smiles>CC(=O)CC=[18O]</smiles><smiles>CC(=O)[SeH]</smiles><smiles>O=C(O)CC(=O)O[Na]</smiles><smiles>CC1CC1C(=O)CC(=O)S(=O)(=O)O</smiles><smiles>O=C(O)CC(=O)OC(=O)O</smiles>

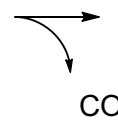<smiles>CC(=O)CC(=O)CC(=O)O[Na]</smiles>

acetyl-CoA malonyl-CoA

acetoacetyl-CoA

Scheme 57 Decarboxylative Claisen reaction to poly- $\beta$-keto esters

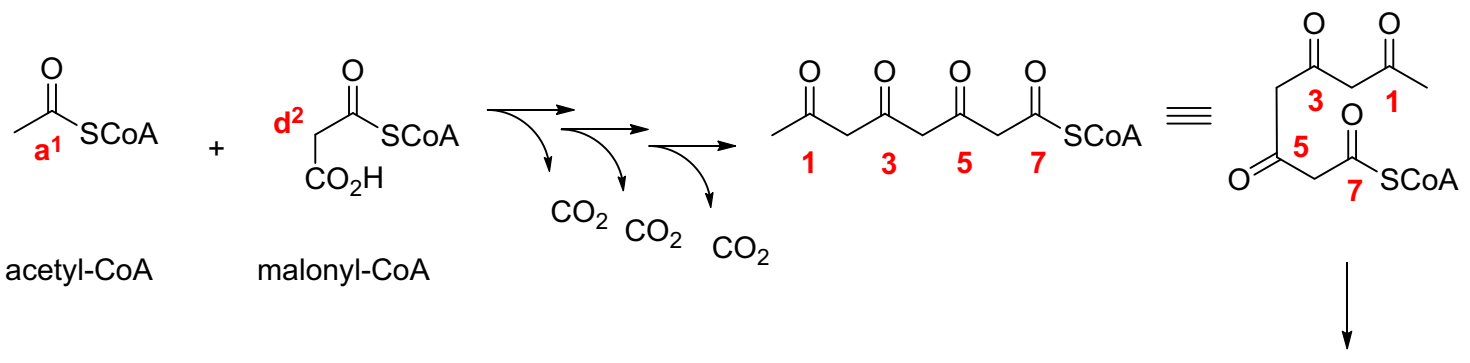

phloracetophenone<smiles>CC(=O)c1c(O)cc(O)cc1O</smiles>

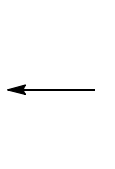<smiles>CC(=O)C1C(=O)CC(=O)CC1=O</smiles>

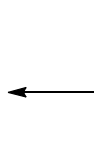<smiles>CC(=O)C1C(=O)CC(=O)CC1(O)S(=O)(=O)O</smiles>

Scheme 58 Access to aromatic polyketide structures-phloracetophenone

Scheme 59 Friedel-Crafts acylation of phloroglucinol to phloracetophenone<smiles>CC(=O)c1c(O)cc(O)cc1O</smiles><smiles>CC(=O)OC(C)=O</smiles>

Friedel-Crafts acylation of phloroglucinol, as depicted in Scheme 59 [33, 34].

However, via this enzymatic intramolecular aldol condensation processes a variety of aromatic polyketide compounds is available. By slight modifications of a consecutive sequence of aldol reactions, aldol condensations, decarboxylation, oxidation and reductions a multitude of different aromatic compounds is accessible. Some examples are depicted in Scheme 60.

In contrast, when using methylmalonyl-CoA instead of malonyl-CoA methylated polyketide structures are accessible by this iterative decarboxylative Claisen reaction. These compounds are important intermediates in the biosynthesis of macrolide antibiotics, namely erythronolides, oleandolides, leuconolides, tylonolide, etc (Scheme 61).

Using propionyl-CoA as the starting unit in six consecutive decarboxylative Claisen reaction of methylmalonyl-CoA, the carbon backbone of the seco-acid of 6-deoxyerythronolide B is formed, the aglycone of erythromycin A. These reactions were catalyzed by a multienzyme complex, containing acyltransferases, dehydratases, enoyl reductases, $\beta$-ketoacyl reductases and thioesterases. This enzymatic $\mathrm{C}-\mathrm{C}$ bond formation process represents an impressive example of the synthesis of 1,3-difunctional compounds (Scheme 62). 
Scheme 60 Aromatic polyketide structures

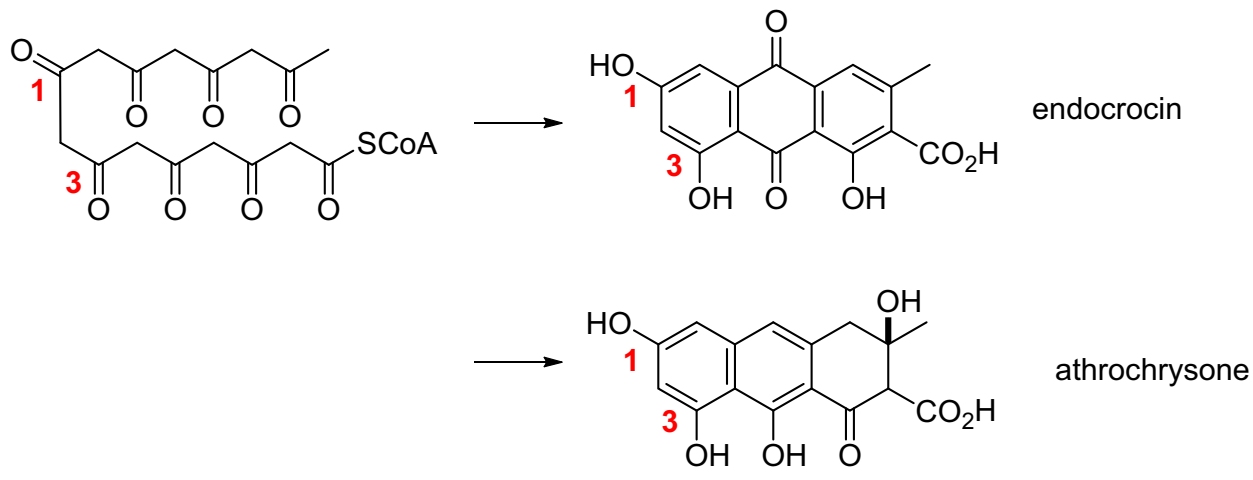<smiles>CCC(=O)SC(=O)OCC(=O)O[Na]</smiles>

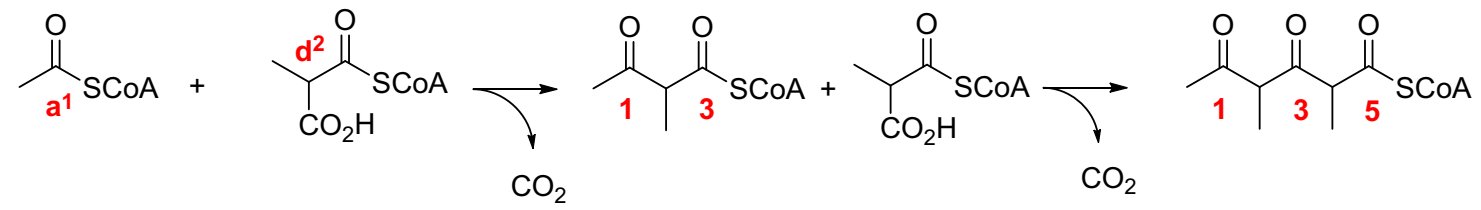

acetyl-CoA methylmalonyl-CoA

Scheme 61 Methylated poly- $\beta$-keto ester

propionyl-CoA methylmalonyl-CoA<smiles>[X]C(C)C(=O)C(=O)OC(=O)O[Na]</smiles><smiles>CC(C)C</smiles><smiles>CCC(O)C(C)[C@@H](O)[C@@H](C)C(=O)C(C)CC(C)[C@@H](O)[C@@H](C)[C@H](O)[C@H](C)C(=O)S(=O)(=O)O</smiles>

$6 \times \mathrm{CO}_{2}$<smiles>C#C</smiles>

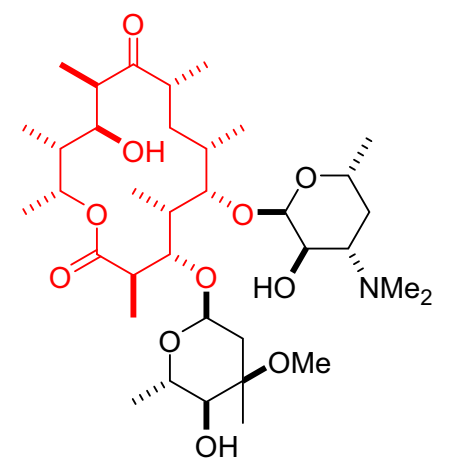
erythromycin A

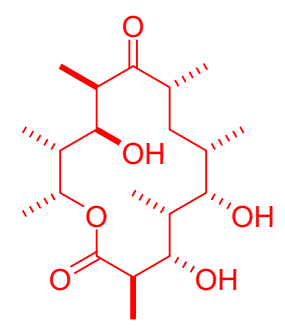
6-deoxyerythronolide B

Scheme 62 Enzymatic access to 6-deoxyerythronolide B

In contrast to the simple chemical synthesis of phloracetophenone (Scheme 59) the total synthesis of deoxyerythronolides constitutes a big challenge. As seen in this chapter, 1,3-difunctional compounds can be easily accessed by aldol additions. Indeed, the synthesis of the carbon skeleton of erythronolides is the field of aldol reactions. 
Scheme 63 Aldol reactions in total synthesis of erythronolide

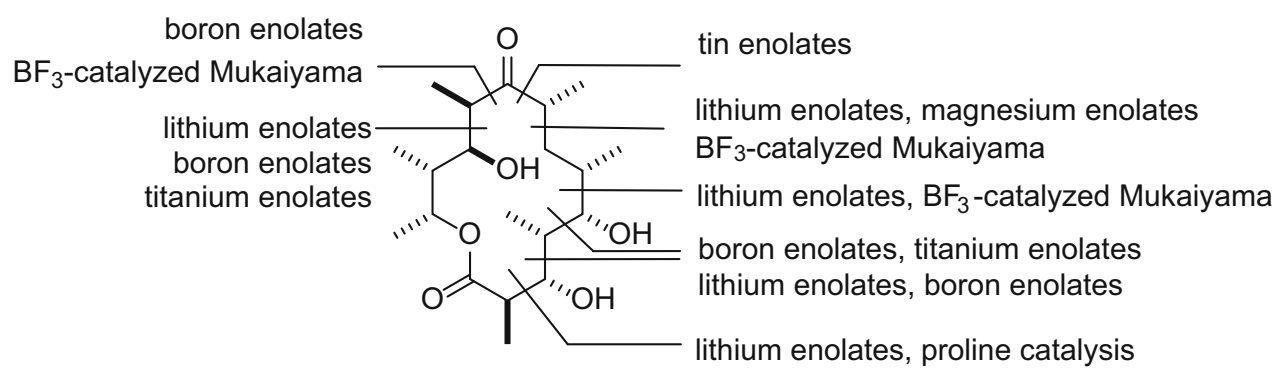

Nearly every $\mathrm{C}-\mathrm{C}$ bond was stereoselectively created by different kinds of aldol additions [35]. This scenario is depicted in Scheme 63.

One of the first who succeeded in this synthesis was $\mathrm{R}$. B. Woodward and a team of excellent chemists [36].

By comparing these two examples of the enzymatic malonyl-CoA and methylmalonyl-CoA series a number of similarities and differences stand out. Based on the application of similar substrates and identical reactions (decarboxylative Claisen reaction) a poly-1,3-difunctional carbon backbone is created in both reactions. However, subsequent intramolecular reactions lead to aromatic polyketide structures in the malonyl-CoA series, whereas by the help of methylmalonyl-CoA an access to macrolide structures is given. Moreover, the chemical synthesis of aromatic polyketide structures (malonyl-CoA) is easy to accomplish, whereas the synthesis of macrolides-products of the methylmalonyl-CoA series-is hard to accomplish. This analysis helps to decide whether a chemical, semichemical or enzymatic process is preferred.

Next, isopentenyl diphosphate represents an important and fundamental intermediate in the biosynthesis of terpenoids. The first step in the biosynthesis of isopentenyl diphosphate is the simple Claisen reaction of two molecules acetyl-CoA. This transformation is followed by an aldol addition of a third molecule acetyl-CoA. Subsequent decarboxylation and dehydration of the tertiary alcohol in the presence of ATP yields isopentenyl phosphate (Scheme 64).

Carbohydrates can be accessed by aldol reactions. Nature accomplishes this transformation by the aid of enzymes, which is depicted in Scheme 65. By the enzymatic aldol reaction of dihydroxyacetone (DHA: $\mathrm{d}^{2}$ donor) and glyceraldehyde ( $\mathrm{a}^{1}$ acceptor) in the presence of RAMA (rabbit muscle aldolase) ketohexoses are accessible (fructose). At the first glance 1,2-difunctional compounds were synthesized. However, this effect is the result of reactions of hydroxylated donors (DHA) and acceptors. By retrosynthetic disconnections of fructose a clear 1,3-difunctional compound resulted by this aldol reaction (indicated in red color).

\section{1,4-Difunctional compounds}

As discussed in the introduction, these compounds are accessible by

- "Umpoled" reactivities and there must be

- Six possibilities to do so.

There are three bonds which can be cleaved and they can be synthesized by two options:

$\mathrm{a} / \mathrm{d}$ and $\mathrm{d} / \mathrm{a}$. These can be combined six possibilities and these six disconnections are depicted in Scheme 66.

Next we will evaluate the practical possibilities of this analysis. The first retrosynthetic step can be realized by a carba-Michael reaction with a $\mathrm{d}^{1}$ synthon-an acyl anion or an "umpoled" carbonyl functionality. As discussed, there are several useful synthons that can be used in this transformation. For this purpose nitro alkanes are the ideal synthons ("umpoled" carbonyl compounds). Thus, by carba-Michael addition of nitro-heptene to methyl vinyl ketone the $\gamma$-nitro ketone is obtained in almost quantitative yields (Scheme 67). This is again a name reaction called the Henry reaction. The conversion of the nitro group into a ketone can be realized by successive treatment with strong bases and strong acids [37]. Again this step is a name reaction called the Nef reaction. Subsequent intramolecular aldol condensation yields jasmone in $78 \%$ yield. At first glance, jasmone is a 1,3-difunctional compound. But the 1,3-disconnection is the result of the last step, the intramolecular aldol condensation of the intermediate 1,4diketone, which is the compound of discussion here (Scheme 67).

Also, 1,4-diketone can be accessed by extensive use of palladium-catalyzed oxidation of terminal olefins (Wacker oxidation, see also Scheme 25). The final intramolecular aldol condensation of the resulting 1,4-diketone yields dihydrojasmone (Scheme 67).

Through reactions of acetylene with aldehydes an access to 1,4-difunctional compounds is given. The corresponding 1,4-diketones can be accessed via a subsequent reduction and following oxidation (Scheme 68). 


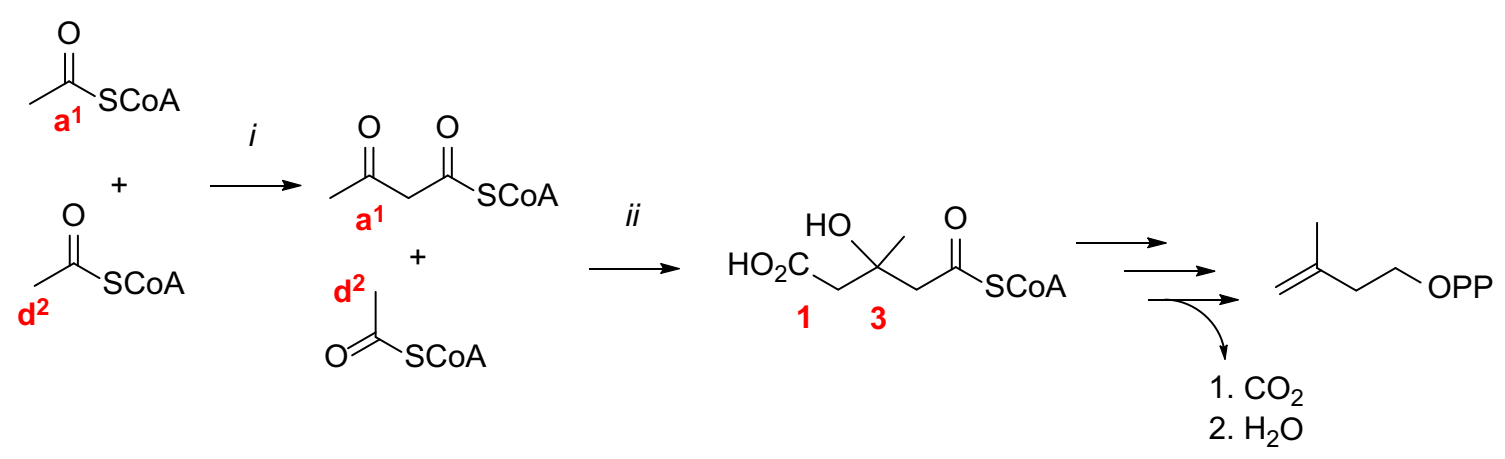

Scheme 64 Formation of isopentenyl diphosphate. $i$ Claisen reaction, $i i$ aldol reaction

Scheme 65 Enzymatic aldol reaction of dihydroxyacetone and glyceraldehyde to fructose<smiles>CCC(C)C1CC1C</smiles><smiles>O=C(CO)C(O)=C(O)C(O)CO</smiles><smiles>C=CC(O)CO</smiles><smiles>O=C(CO)CO</smiles><smiles>OCC(O)CO</smiles><smiles>O=CCO</smiles><smiles>C=COCC(=O)C(O)=C(O)C(O)C(O)CO</smiles>

The classical route to 1,4-difunctional compounds is a reaction of $\alpha$-bromo carbonyl compounds ("umpoled" $\mathrm{a}^{2}$ acceptor) with natural $\mathrm{d}^{2}$-donators. This can easily be accomplished by the classical Storck-enamine chemistry [38] (Scheme 69).

Palladium-catalyzed reactions of $\alpha$-halo ketones with tributyl tin enolates provide a further access to 1,4-diketones (Scheme 70). Using this methodology dihydrojasmone was isolated in approximately $60 \%$ [39].

Moreover, 1,4-diketones can be obtained by a decarboxylative opening of epoxides. This methodology consists of successive treatment of ethyl acetoacetate and a terminal epoxide with sodium and subsequent reactions with hydrochloric acid [40] (Scheme 71).

1,4-Difunctional compounds are products of the socalled Barbier reaction of $\beta$-bromocarbonyl compounds with aldehydes. The required "umpolung" step from a natural $\mathrm{a}^{3}$ acceptor to $\mathrm{a} \mathrm{d}^{3}$ donor (carbanion) is achieved by the reaction of $\beta$-bromocarbonyl compound with zinc (oxidative insertion of zinc). Zinc is used in these transformations to avoid troublesome reactions with the carbonyl compounds (1,2-addition, aldol reaction, etc.) (Scheme 72).

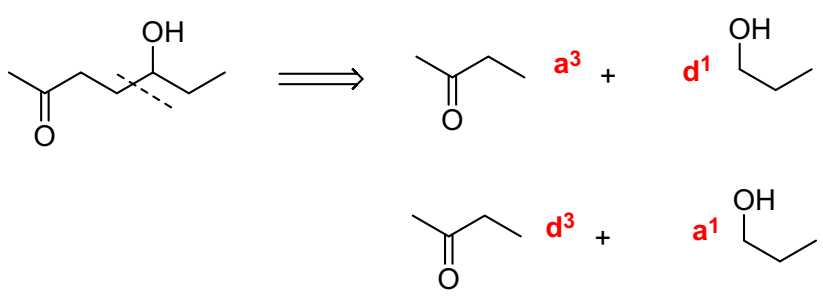<smiles>C=C=CC(C)=O</smiles><smiles>C=CCCC(O)C=CC(C)=O</smiles>

Scheme 66 Retrosynthetic analysis of 1,4-difunctional compounds 
<smiles>C=CCC1(C)C(=O)CCC1C</smiles>

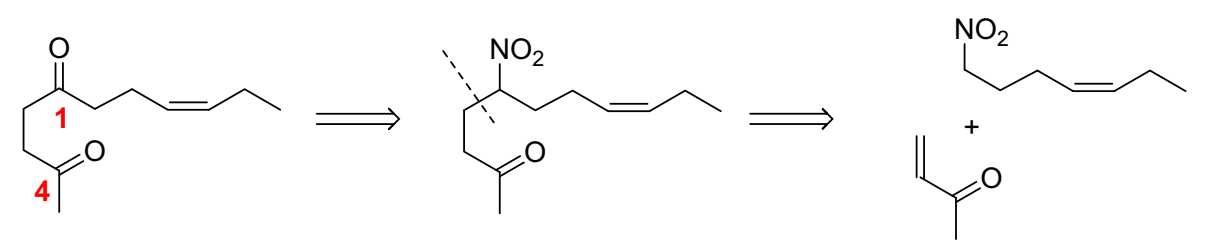<smiles>C=CC(C)=O</smiles><smiles>C=CCCC(=O)CCCCCCC(=O)CCCCCC(C)C(=O)OCCO</smiles>

dihydrojasmone<smiles>CCCCCC1=C(C)CCC1=O</smiles>

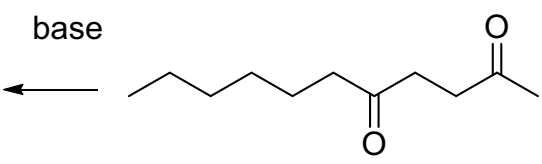

Scheme $67 \mathrm{a}^{3} / \mathrm{d}^{1}$ Access to jasmone and dihydrojasmone<smiles>C#CC(C)OC(C)C#CC(C)=O</smiles>

Scheme $68 \mathrm{~d}^{3} / \mathrm{a}^{1}$ Approach to 1,4-difunctional compounds 
Scheme $69 \mathrm{a}^{2} / \mathrm{d}^{2}$ Access to 1,4-diketones<smiles>C=CCC(C)=O</smiles><smiles>CCCCCCCC(=O)CCC(C)=O</smiles>

Scheme $70 \mathrm{~d}^{2} / \mathrm{a}^{2}$ Access to 1,4-difunctionalized compounds<smiles>CCOC(=O)CC(C)=O</smiles>

Scheme $71 \mathrm{~d}^{2} / \mathrm{a}^{2}$ Access to 1,4-difunctional compounds

As discussed above, acyl anions are valuable "umpoled" synthons that act as $\mathrm{d}^{1}$ donors in the Michael addition. Thus when used with palladium acyl complexes 1,4-diketones were obtained in carba-Michael additions (Scheme 73) [41].

Aldehyde ( $\mathrm{a}^{1}$ acceptors) can be transformed into a $\mathrm{d}^{1}$ donator by addition of cyanides (benzoin addition) or by reactions with the ylides of thioazolium salts. The latter is again a name reaction, the Stetter reaction, and is depicted in Scheme 74 [42]. The use of thiazolium salts was discussed in the 1,2-difunctional series (Scheme 36). Based on the unnatural reactivity an "umpolung" is required. This is achieved by adding cyanide to the carbonyl compound or reacting with the thiazolium salt (thiamine analog). A subsequent conjugate addition yields the corresponding 1,4-diketone. The benzoin addition does not work with<smiles>CCCCC(=O)C(C)CC(=O)CC</smiles>

Scheme $73 \mathrm{~d}^{1} / \mathrm{a}^{3}$ Access to 1,4-difunctional compounds by carbaMichael reactions with palladium-acyl complexes

aliphatic aldehydes, therefore the Stetter reaction is favored for the formation of an aliphatic acyl anion.

An example of an intramolecular Stetter reaction is depicted in Scheme 75. The functionalized benzaldehyde was "umpoled" from an $\mathrm{a}^{1}$ acceptor to a $\mathrm{d}^{1}$ donor by the reaction with $N$-alkylthiazolium-based ionic liquid, to react with the $\mathrm{a}^{3}$ acceptor of the substituted acrylic ester. Thus, 1,4-difunctional compounds can be accessed by an intramolecular Stetter reaction [43].

On this point it should be remembered that by the choice of reaction conditions an optional access to 1,2- or 1,4-difunctional compounds can be realized. This is demonstrated in the utilization of acylcirconocene complexes. A formal "umpolung" of an aldehyde ( $\mathrm{a}^{1}$ acceptor) to a $\mathrm{d}^{1}$ donor followed by a palladium-catalyzed reaction with $\alpha, \beta$-unsaturated ketones yields 1,2- or 1,4-difunctional compounds (Scheme 76).<smiles>CCC(=O)CCBr</smiles>

Scheme $72 \mathrm{a}^{1} / \mathrm{d}^{3}$ Approach by Barbier reaction 


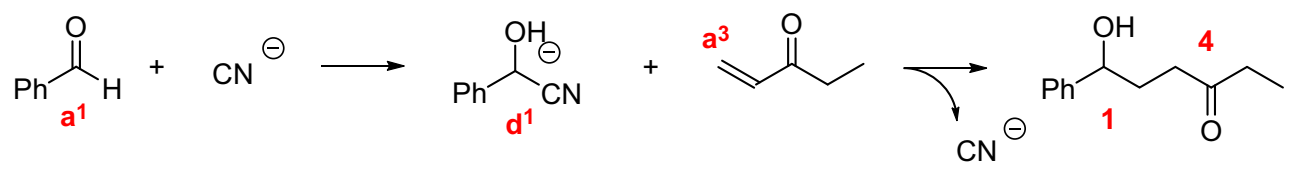<smiles>CCC(=O)CCC(C)=O</smiles>

Scheme $74 \mathrm{~d}^{1} / \mathrm{a}^{3}$ Difunctional compounds by "umpolung" reactions-benzoin addition and Stetter reaction

Scheme 75 Intramolecular Stetter reaction<smiles>[R]c1ccc(OCC=CC(C)=O)c(C=O)c1</smiles><smiles>CCC[n+]1ccsc1</smiles><smiles>[R]c1ccc2c(c1)C(=O)C(CC(C)=O)CO2</smiles><smiles>[R]C=O</smiles>

1,2-addition $\mathrm{Pd}^{2+}$<smiles>C1CCCC1</smiles><smiles></smiles> 

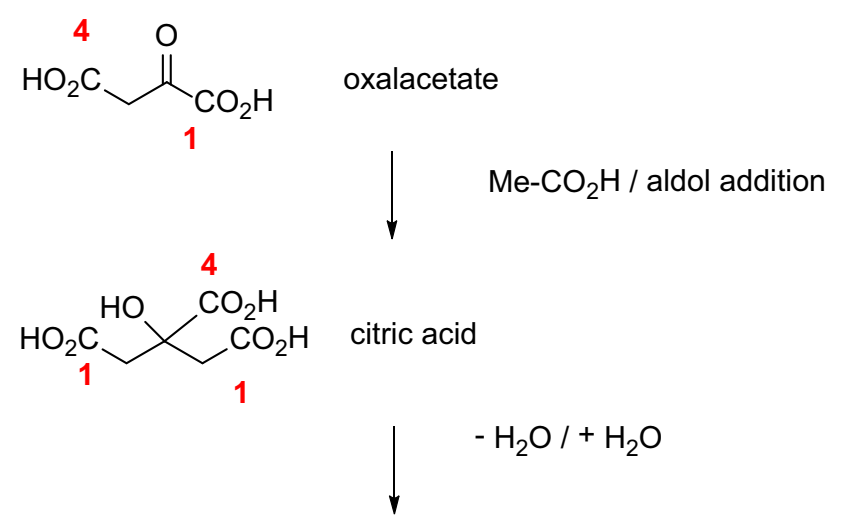

$\underbrace{\mathrm{HO}_{2} \mathrm{C}}_{\mathrm{OH}} \underbrace{\mathrm{CO}_{2} \mathrm{H}}_{1}$ isocitrate

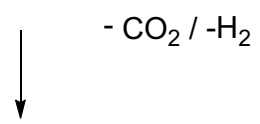

$\mathrm{HO}_{2} \mathrm{C} \underbrace{\mathrm{CO}_{2} \mathrm{H}}_{1}$

ketoglutarate
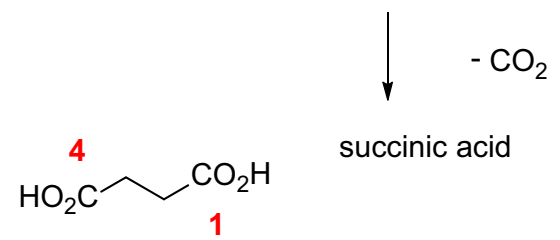

succinic acid

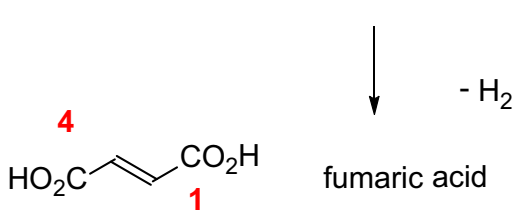

Scheme 77 1,4-Difunctional intermediates in citric acid cycle

emerged as the "umpolung" process, which re-merged on a later stage as the 1,4-difunctional tertiary alcohol [44] (Scheme 78).

\section{1,5-Difunctional compounds}

1,5-Difunctional compounds are accessible by natural reactivities. Based on the rules of the introductory text there are four carbon bonds, which can be cleaved (Table 1). Allowing for the two optional alternatives $(\mathrm{a} / \mathrm{d}$ and $d / a)$, there are eight possibilities to synthesize 1,5 - difunctionalized compounds. These options are depicted in Scheme 79.

The first reaction can be realized by "umpolung" of both substrates. $\gamma$-Bromo ketone ( $\mathrm{a}^{4}$ acceptor) reacts with the lithiated $\mathrm{d}^{1}$ donor to yield the required 1,5-difunctional compound (Scheme 80).

The starting $\gamma$-bromo ketone $\left(\mathrm{a}^{4}\right.$ acceptor) can be "umpoled" by the formation of the corresponding carbanion with zinc $\left(\mathrm{d}^{4}\right.$ donor). Subsequent reaction with an aldehyde ( $\mathrm{a}^{1}$ acceptor) yields the desired 1,5-difunctional compound (Scheme 81).

The $\mathrm{a}^{3} / \mathrm{d}^{2}$ access is the field of the classical conjugate addition. Again this is a name reaction, the carba-Michael reaction. This transformation is based on natural reactivities. Numerous reports of the application of this reaction were published. An illustrative example is depicted in Scheme 82. The carba-Michael addition of malonic acid ester to acrylic acid ester yields the expected 1,5-difunctional ester.

The formation of the Wieland-Miescher ketone is a valuable example of a cascade reaction of the carbaMichael addition (conjugate addition, 1,5-difunctional) followed by an aldol reaction (1,3-difunctional). This reaction sequence is yet again a name reaction, the Robinson annulation (see also Scheme 47 in the 1,3-difunctional series). Due to its reliability and its high regioand stereoselectivity, the Robinson annulation is often used in the total synthesis of steroids, even on an industrial scale. An application is depicted in Scheme 83. Based on the deployment of cyclic ketones an access to steroids is given by the successive deployment of ethyl vinyl ketone and methyl vinyl ketone in carba-Michael reactions.

Also, in Scheme 84 some examples are depicted for the application of conjugate additions in cascade reactions. Most often the carba-Michael addition is followed by an aldol condensation to construct selectively required ring systems.

In the acyclic series this natural reactivity can be exploited to synthesize the corresponding 1,5-diketone in an operationally simple protocol. The further selective reduction to the $\delta$-hydroxy ketone though causes problems (Scheme 85).

The next disconnection - the reaction of $\mathrm{d}^{3}$ donor with an $\mathrm{a}^{2}$ acceptor-is again a transformation of two "umpoled" substrates (Scheme 86). The natural reactivity of an $\mathrm{a}^{3}$ acceptor has to be "umpoled" to a $\mathrm{d}^{3}$ donor and the reactivity of the $d^{2}$ donor has to be changed into an $\mathrm{a}^{2}$ 


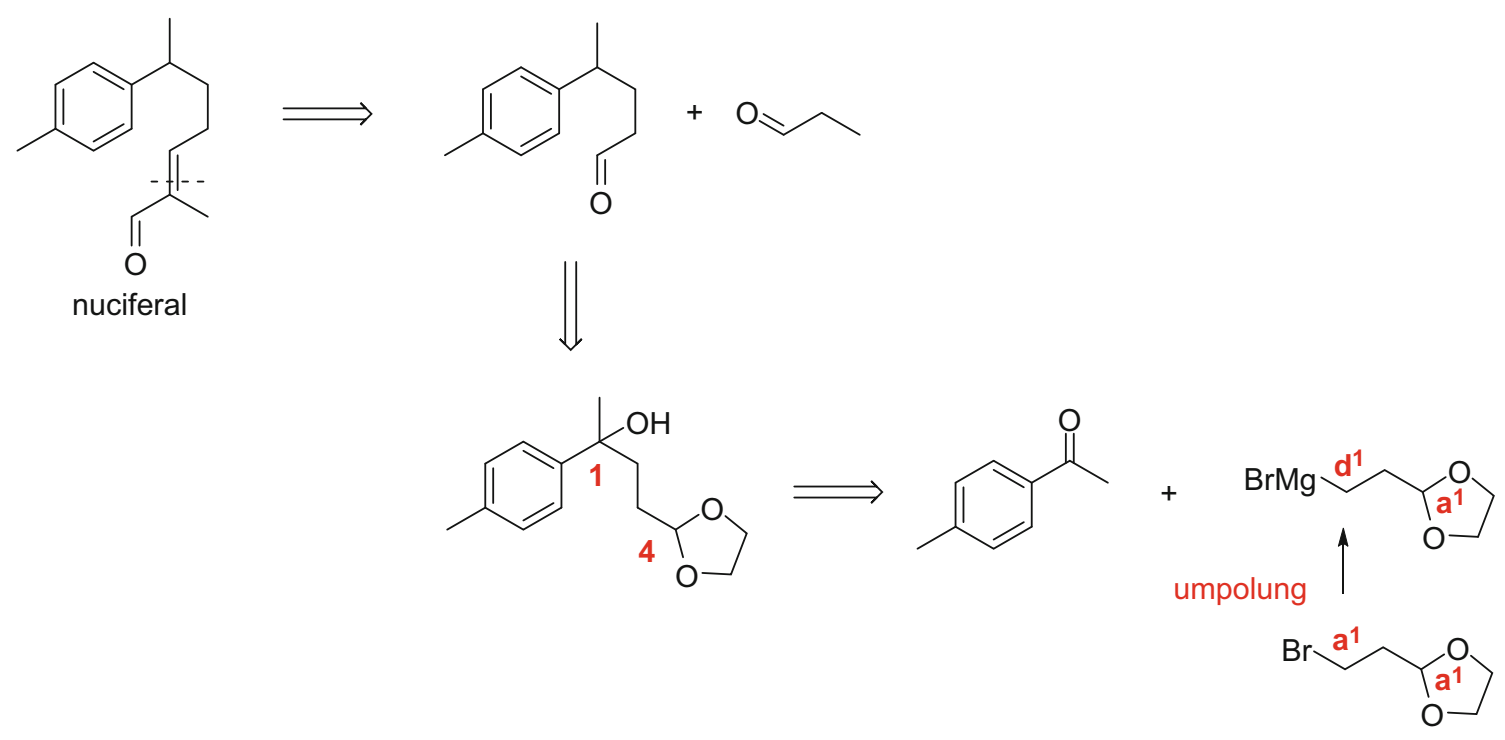

Scheme 78 Retrosynthetic disconnection of nuciferal

acceptor. This can easily be realized by the generation of the $\mathrm{a}^{3}$ carbanion of the $\beta$-bromo ketone and subsequent reaction with the terminal epoxide to give the $\delta$-hydroxy ketone (1,5-difunctional compound).

The next retrosynthetic disconnection of Scheme 87 is again a reaction of "umpoled" synthons $\left(\mathrm{a}^{2} / \mathrm{d}^{3}\right)$ and represents due to the symmetry formally the reversal of the disconnection above $\left(\mathrm{d}^{3} / \mathrm{a}^{2}\right.$, Scheme 86$)$. However, the required $\delta$-hydroxy ketone is not a symmetric compound. To this end a long way of FGI has to be realized to the same $\delta$-hydroxy ketone as depicted in Scheme 86 (Scheme 87). Due to the different oxidation states (ketone/ secondary alcohol) an extensive utilization of orthogonal functional groups is required (Scheme 87).

The next disconnection-the $\mathrm{d}^{2} / \mathrm{a}^{3}$ step-is formally again a reversal of the disconnection $\mathrm{a}^{3} / \mathrm{d}^{2}$ (Scheme 85 ). The synthesis can be realized by the application of natural reactivities. By reaction of acetone with methyl vinyl ketone an access to the $\delta$-hydroxy ketone is possible. An intermediate carboxylation of acetone supports this carbaMichael addition [45] (Scheme 88). But the next step, the selective reduction of one keto-functionality-the formation of the desired hydroxy ketone-will be hard to realize. To this end another approach has to be found (same situation as in Scheme 85).

The seventh disconnection is a reaction based on natural reactivities. Again we start with the decarboxylative bromination of the $\gamma$-lactone (compare with Scheme 80) [46]. The resulting $\mathrm{a}^{4}$ acceptor is converted into the corresponding $\mathrm{d}^{4}$ donor. This "umpolung" was realized by means of zinc. The subsequent reaction with acetaldehyde generates a $\delta$-hydroxy ketone, however in inverted oxidation states. A subsequent extensive FGI helps to synthesize the desired $\delta$-hydroxy ketone. The use of orthogonal protective manipulation is necessary (Scheme 89).

The last synthetic option is realized by the complete "umpolung" of the reactivities of the $\mathrm{a}^{1} / \mathrm{d}^{4}$ disconnection. Starting with the "umpolung" of acetaldehyde the resulting lithiated dithiane reacts with the protected $\gamma$-bromo ketone to yield the desired carbon backbone. By subsequent deprotection/reduction sequence the secondary alcohol can be obtained. The deprotection of the dithiane yields the desired $\delta$-hydroxy ketone (Scheme 90).

The final evaluation of these retrosynthetic disconnections of the 1,5-difunctional compounds produces the following situation.

Two of the eight synthetic possibilities give no satisfactory answers $\left(\mathrm{a}^{3} / \mathrm{d}^{2}\right.$ and the corresponding synthon pair $\left.\mathrm{d}^{2} / \mathrm{a}^{3}\right)$. The regioselective reduction of 1,5 -diketones is a dead end (with the exception of special substrates in enzymatic reductions).

The shortest sequence is provided by the $\mathrm{d}^{4} / \mathrm{a}^{1}$ disconnection. The required $\delta$-hydroxy ketone can be synthesized 
Scheme 79 Retrosynthetic map of 1,5-difunctional compounds<smiles>CCCC(C)=O</smiles><smiles>C=CCC(O)CCCC(C)=O</smiles><smiles>CCC(C)=O</smiles><smiles>C=CCC(O)CCC(C)CC(C)=O</smiles><smiles>CCC(O)CC</smiles><smiles>C=CC(=O)CCC(O)CCCC(C)=O</smiles><smiles>CC=CC(O)CCC</smiles><smiles>CC(=O)C1CCOC1=O</smiles><smiles>[3H]Br</smiles>

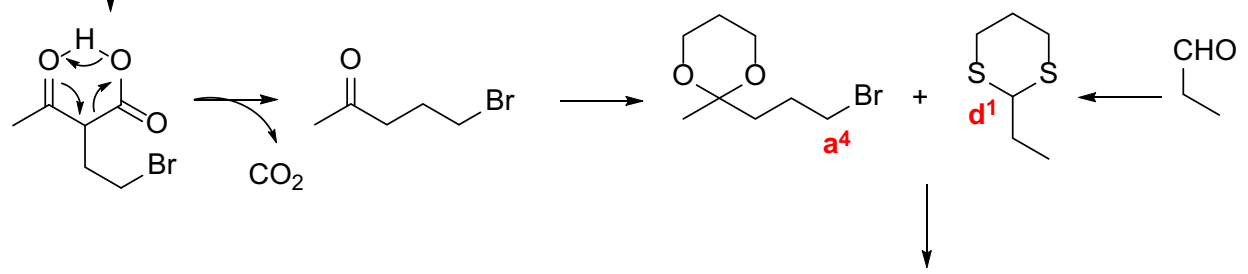<smiles>CCC(=O)CCCC1(C)OCCCO1</smiles>

Scheme $80 \mathrm{a}^{4} / \mathrm{d}^{1}$ Access to 1,5-difunctional compounds 


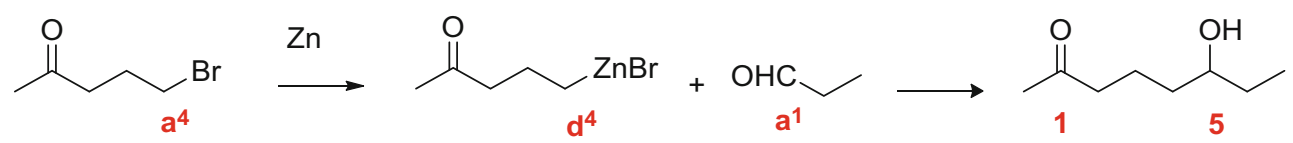

Scheme $81 d^{4} / a^{1}$ Access by Barbier-type reaction

Scheme 82 1,5-Difunctional compounds by carba-Michael addition $\left(\mathrm{a}^{3} / \mathrm{d}^{2}\right)$

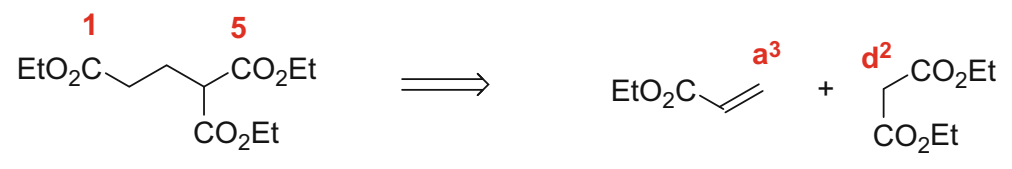

$\mathrm{EtO}_{2} \mathrm{C}+\Gamma_{\mathrm{CO}_{2} \mathrm{Et}}^{\mathrm{CO}_{2} \mathrm{Et}} \longrightarrow \mathrm{EtO}_{\mathrm{CO}_{2} \mathrm{Et}}^{\mathrm{CO}_{2} \mathrm{Et}}$<smiles>C=CC(C)=O</smiles><smiles>C=CC(C)=O</smiles>

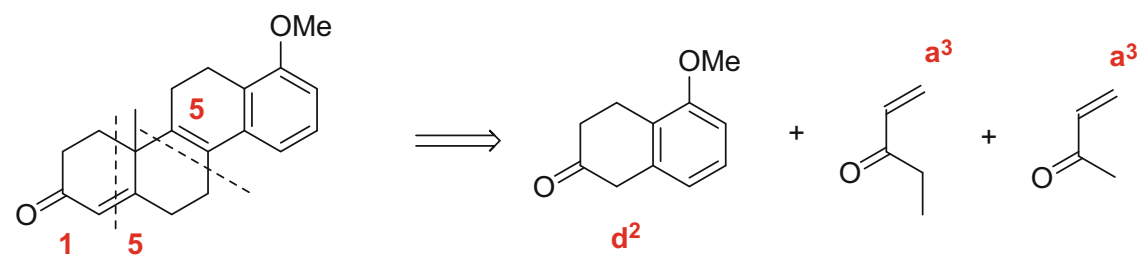<smiles>CCC(=O)CCC(=O)CC</smiles><smiles>CCC(=O)CCC1C(=O)CCc2c(OC)cccc21</smiles><smiles>C=CC(C)=O</smiles><smiles>COc1cccc2c1CCC1=C2CCC2=CC(=O)CCC21C</smiles>

Scheme 83 Addition of $\mathrm{d}^{2}$ donors to conjugate systems ( $\mathrm{a}^{3}$ acceptor)—Robinson annulation 
<smiles>C=CC(=O)CCC1CCC(CCC(=O)CC)C(=O)C=C1c1ccccc1</smiles><smiles>COc1ccc2c(c1)CCCC2=O</smiles>

Scheme 84 Cascade reactions to steroids (carba-Michael/aldol condensation)

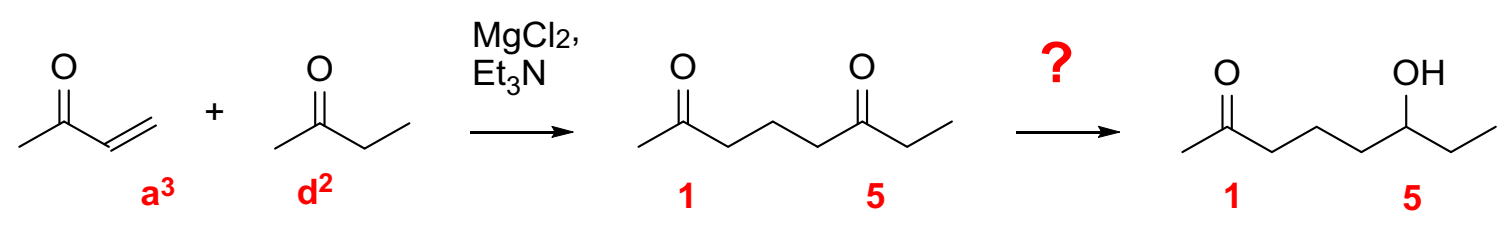

Scheme 85 Carba-Michael reaction-an $\mathrm{a}^{3} / \mathrm{d}^{2}$ access to 1,5-difunctional compounds<smiles>CC(=O)CCBr</smiles><smiles>CCCC1(C)OCCO1</smiles><smiles>CCC1[CH]O1</smiles><smiles>CCC(O)CCCC1(C)OCCO1</smiles><smiles>CCC(O)CCCC(C)=O</smiles>

Scheme $86 \mathrm{~d}^{3} / \mathrm{a}^{2}$ Access to $\delta$-hydroxy ketones

by only two reaction steps. The longest route to this compound provides the $\mathrm{a}^{2} / \mathrm{d}^{3}$ disconnection. In this case seven reaction steps are necessary due to the inverted oxidation states. In the middle field there are synthetic sequences with three, four and six reaction steps. These retrosynthetic pathways serve as a standard for all other synthetic problems. Based on the substrates, the availability of these substrates, the yields of reaction steps, the reliability of the reactions and the chemoselectivity a synthetic route has to be elaborated.

Similar considerations can be made for 1,6-difunctional compounds and 1,7-difunctional compounds. 
<smiles>CCC(=O)CCBr</smiles><smiles>CCC(=O)CCCC(C)O</smiles><smiles>[R6]OC(C)CCCC(=O)CC</smiles><smiles>CCC(O)CCCC(C)O[Ga]C</smiles><smiles>CCC(CCC(C)OC(CC)CCCC(C)O)OC(C)C</smiles><smiles>CCC(O)CCCC(C)=O</smiles>

Scheme $87 \mathrm{a}^{2} / \mathrm{d}^{3}$ Access to 1,5-difunctional compounds

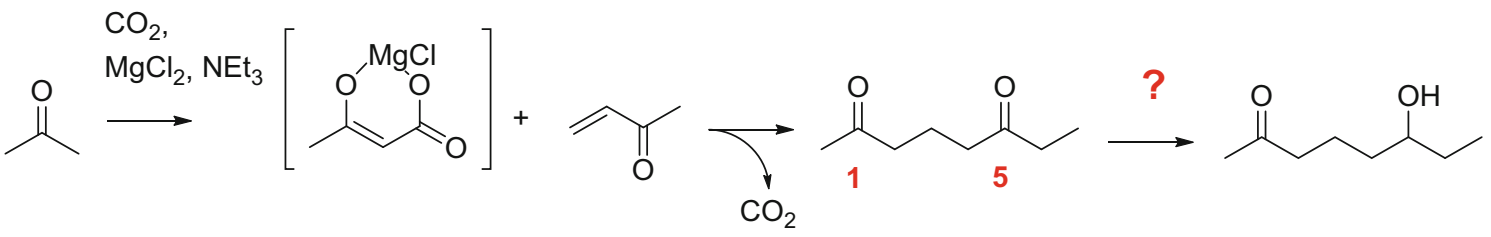

Scheme $88 \mathrm{~d}^{2} / \mathrm{a}^{3}$ Access to difunctional compounds<smiles>CCOC(=O)CC(C)=O</smiles><smiles>CC(=O)C1CCOC1=O</smiles><smiles>O=C(O)CCCCCC(=O)O</smiles><smiles>CC(=O)CCCBr</smiles>
$\mathrm{Me}-\mathrm{CHO}+$<smiles>CC(=O)CCCBr</smiles><smiles>CCC(=O)CCCC(C)O</smiles><smiles>CCC(O)CCCC(C)OC(C)C</smiles><smiles>CCC(O)CCCC(C)=O</smiles>

Scheme $89 \mathrm{a}^{1} / \mathrm{d}^{4}$ Access to 1,5 -difunctional compounds 


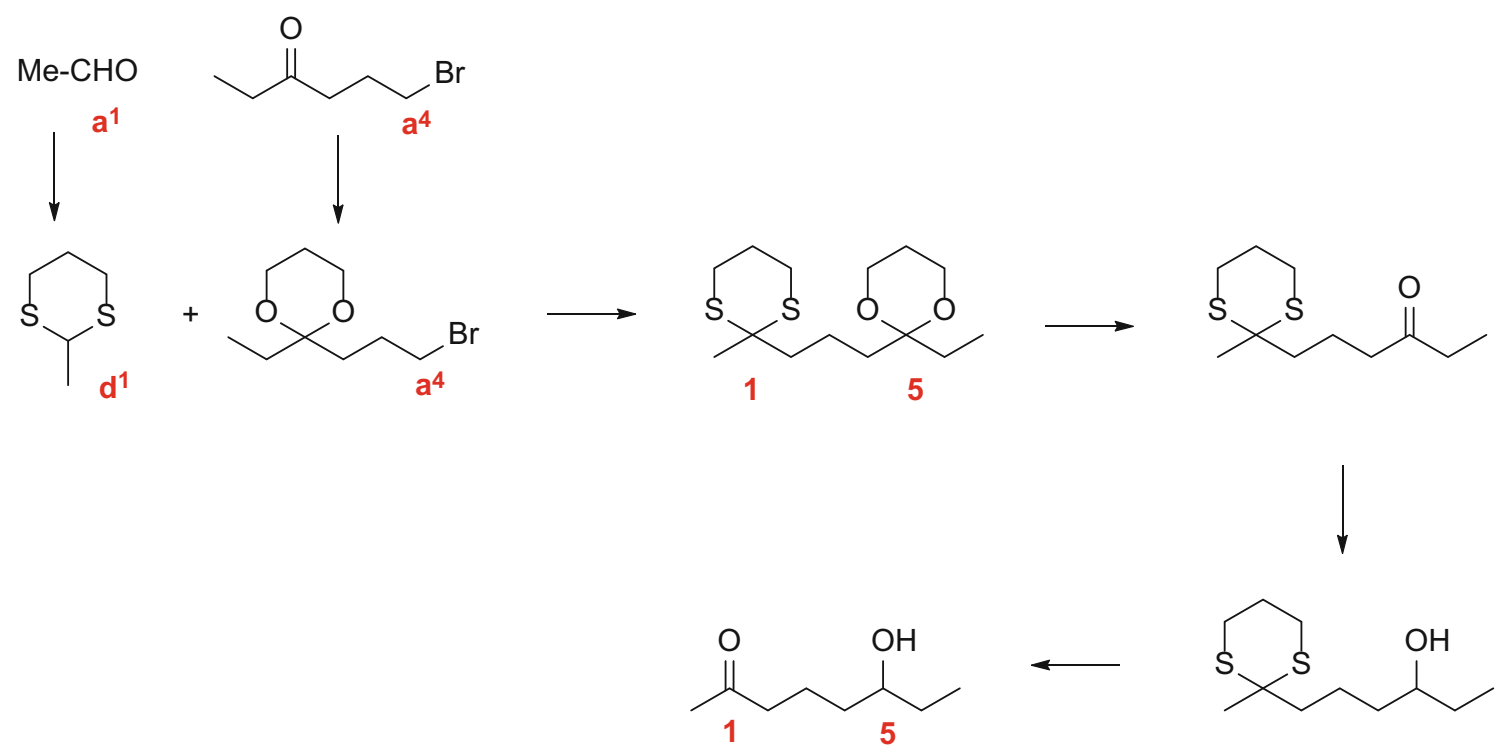

Scheme $90 \mathrm{~d}^{1} / \mathrm{a}^{4}$ Access to 1,5-difunctional compounds

\section{1,6-Difunctional compounds}

Instructive examples of these series are rare. This is due to the long distance between the functionalities (1,6 or $1,7)$, which represents lower density of functional groups and is more representative for hydrocarbons. Moreover, if there are additional functionality groups between these distances a clear and logic retrosynthetic analysis will be confusing and complicated (see example of steroid oxidation in Scheme 95). The possible disconnections for 1,6-difunctional compounds are depicted in Scheme 91.

A full synthetic description to all ten retrosynthetic disconnection should not be given for reasons discussed above.

Nevertheless, there are some illustrative examples and these should be mentioned here. The gold-catalyzed hydration of terminal alkynes yields methyl ketones. Thus, when used with 1,7-octadiin the corresponding 2,7-octanedione can be obtained (Scheme 92).

Also, the oxidative cleavage of cyclohexenes is an excellent source for 1,6-difunctional compounds. Everybody knows this simple OC 1 - experiment, the formation of adipic acid by treatment of cyclohexene with hydrogen peroxide. Again, this is a name reaction, the Bayer-Villiger oxidation (Scheme 93).

Also, cyclic 1,2-diols can be cleaved by oxidation and thus lead to difunctional compounds [47]. When used with cyclohexyl-1,2-diols 1,6-difunctional compounds were obtained. In contrast, when used with cyclopentyl-1,2-diols an access to 1,5-difunctional compounds is given. In this case the ring size of 1,2-diols determines the distance of functionalities of corresponding diketones (Scheme 94).

This simple access to 1,6-dicarbonyl compounds has been used in a great many synthesis of the steroid carbon backbone. One example should illustrate that. The required diketone in Scheme 95 represents a 1,6 difunctional compound. Oxidation of the double bond of ketone yields a triketone. By a subsequent intramolecular aldol condensation the formation of the cyclic $\alpha, \beta$-unsaturated ketone is accomplished (1,6-difunctional) [48].

In this way, to construct the carbon backbone of steroids, we have discussed that in the 1,3-difunctional series. And indeed, the intramolecular aldol condensation of the triketone is the Robinson annulation, which was discussed in Scheme 47. This example demonstrates how complicated the analysis will be if more than two functionalities are included.

Also, as mentioned above, the greater the distance between two functionalities, the greater the number of synthetic possibilities or disconnections, which do not follow the formal retrosynthetic disconnections of Scheme 91 . This is demonstrated by an instructive example as depicted in Scheme 96.

Independent of the logic retrosynthetic disconnections discussed above (Scheme 91), 1,6-difunctional compounds can also be accessed by combining $\mathrm{C} 2 / \mathrm{C} 4 / \mathrm{C} 2$ synthons. This was achieved by the extensive use of "umpoled" dithianes 
Scheme 91 1,6-Difunctional retrosynthetic disconnections<smiles>C=CCC(=O)CCCCC(=O)CCCC(=O)CCC</smiles><smiles>CCCCC(=O)CC</smiles><smiles>C=C(C=CCCC(=O)CC)CC</smiles><smiles>C1=CCCC=C1</smiles><smiles>CCCC(=O)CC</smiles>
$+$<smiles>CC(=O)c1ccccc1</smiles><smiles>CCCC(=O)CC</smiles><smiles>CC(=O)c1ccccc1</smiles><smiles>C=C(CCC(C)=O)CCC(C)=O</smiles><smiles>C=C</smiles><smiles>CCC(=O)CC</smiles>
$+$<smiles>CC(=O)C[Ge]</smiles><smiles>CCC(=O)CC</smiles>

$+$<smiles>CCC(C)=O</smiles><smiles>CCC(=O)CCCC(C)=O</smiles><smiles>C=C</smiles><smiles>CCC(C)=O</smiles>

$+$<smiles>CCC(C)=O</smiles><smiles>[CH2]CCC(C)=O</smiles><smiles>C=C=CCCCC(C)=O</smiles><smiles>CCC=O</smiles>

$+$<smiles>CCCCC(C)=O</smiles><smiles>CCC(=O)[AlH2]</smiles>

$a^{5}$<smiles>CCCCC(C)=O</smiles>

Scheme 92 Gold-catalyzed hydration of terminal alkynes

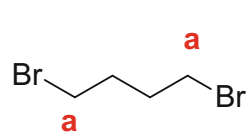<smiles>[TeH3-]</smiles><smiles>CC(=O)CCCCC(C)=O</smiles> 


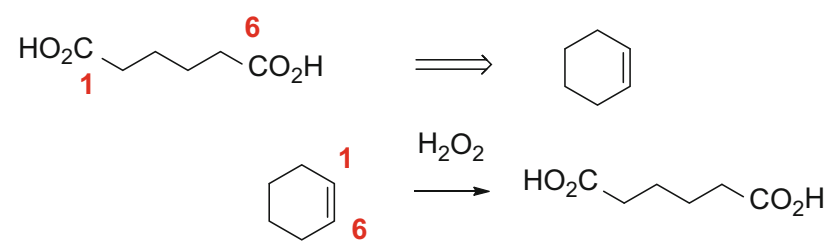

Scheme 93 Bayer-Villiger oxidation of cyclohexene<smiles>CC1(O)CCCCC1(C)O</smiles>

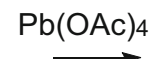<smiles>CC(=O)CCCCC(C)=O</smiles><smiles>CC1(O)CCCC1(C)O</smiles><smiles>[Mg]O[Pb]</smiles><smiles>CC(=O)CCCC(C)=O</smiles>

Scheme 94 Oxidative cleavage of cyclic 1,2-diols

by the Seebach group. During the total synthesis of vermiculine a 1,6- difunctional synthons was needed [49].

\section{1,7-Difunctional compounds}

An instructive example for 1,7-difunctional compounds is depicted in Scheme 97. Due to the substitution pattern of the $\beta$-position of the $\alpha, \beta$-unsaturated ketone a carbaMichael addition is not possible at this point. The $\mathrm{C}-\mathrm{C}$ bond formation process takes place in $\delta$-position. A 1,7difunctional compound is the result of this reaction [50].

\section{Summary}

With this system of a logic disconnection or construction of organic molecules a tool is given to overcome serious problems in the study of organic chemistry. Thus, a solution is given to the inflationary trend of name reactions. Based on the logic system of polar reactions of donors and acceptors several different reactions can be created to access a required target molecule. By a following careful analysis of these proposals several transformations can be detected as the preferred ones. Moreover, by the introduction of the "umpolung" principle additional options are given to synthesize a required molecule. These considerations were discussed in the 1,2-, 1,3-, 1,4-, 1,5- and 1,6difunctional series. Examples demonstrate the power of the principle of the logic of organic chemistry.

\section{Glossary}

Acceptor: electrophile

Donor: nucleophile

Synthon: Synthons are "structural units within a molecule which are related to possible synthetic operations" E. J. Corey

FGI: functional group interconversion<smiles>CCCCC1CCC2C3CCC4=CC(=O)CCC4(C)C3C(=O)CC12C</smiles><smiles>CCC[O+]=[SH](C)(C)C</smiles><smiles>CCCCO[OH+]C1CCC2C3CCC(=O)C4(C)CCC(C)=C(CC12C)C34</smiles>
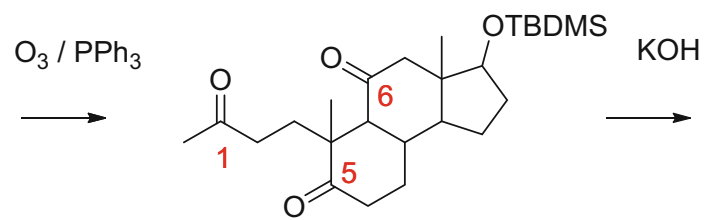<smiles>CCCCO[C+]C1CCC2C3CCC4=CC(=O)CCC4(C)C3C(=O)CC12C</smiles>

Scheme 95 1,6-Difunctional compounds by cascade reactions (oxidation/Robinson annulation) 
<smiles>CC(=O)CC(CCC(=O)/C=C/C(=O)OC(CCC(=O)/C=C/C(=O)O)CC(C)=O)OC(C)=O</smiles><smiles>C=C</smiles>

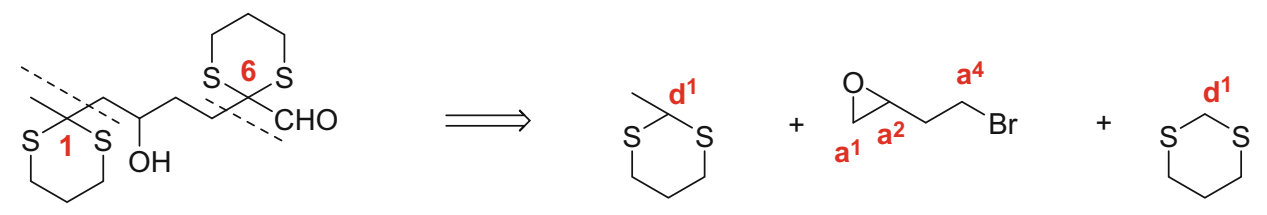

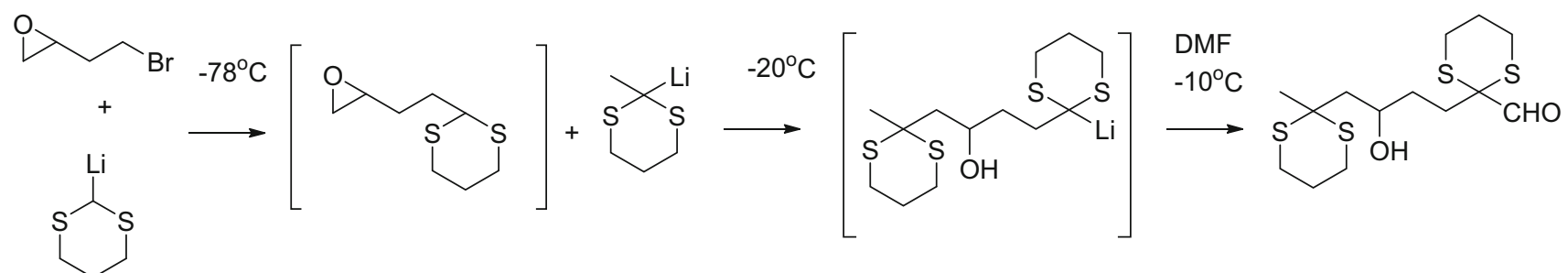

Scheme $96 \mathrm{~d}^{2} / \mathrm{a}^{4} / \mathrm{d}^{2}$ Access to 1,6-difunctional compound (vermiculine)

Scheme 97 1,7-Difunctional compounds<smiles>CCOC(=O)C(C)C(C)OCC</smiles>

Umpolung: any process which reverses the polarity (polarity inversion)

\section{References}

1. Lee AWM, Tse CL (1994) J Chem Educ 71:1071-1072

2. Retrosynthesis is the intellectual (theoretical) disconnection of a target molecule into simple and readily available starting materials. see Corey EJ, Cheng XM (1995) The logic of chemical synthesis, Wiley, NY

3. Lapworth AJ (1898) Chem Soc 73:445-459

4. Saltzman M (1972) J Chem Educ 49:750-752

5. Corey EJ (1967) Pure Appl Chem 14:19-38

6. The term "natural" is not connected with the occurrence in nature. Even Nature is working with "umpolung" methods. See decarboxylation- and carboxylation-processes, biochemical formation of cyanohydrins. We use this term in this report to clearly and precisely differentiate between the "umpoled" reactivity and the normal (natural) reactivity

7. Seebach D (1979) Angew Chem Int Ed 18:239-258

8. Schroeder F, Fettköther R, Noldt U, Dettner K, König WA, Francke W (1994) Liebigs Ann Chem 1211-1218

9. Katzenellenbogen JA, Bowlus SB (1973) J Org Chem 38:627-632

10. Leyva A, Corma A (2009) J Org Chem 74:2067-2074

11. Alvarez P, Bassetti M, Gimeno J, Mancini G (2001) Tetrahedron Lett 42:8467-8470

12. Reppe W (1955) Justus Liebigs Ann Chem 596:38-79

13. Brown HC, Chen J (1981) J Org Chem 46:3978-3988

14. Bäckvall JE (1978) Tetrahedron Lett. 163-166

15. Lundt I; Madsen R (1995) Synthesis 787-794

16. Brochu MP, Brown SP, MacMillan DWC (2004) J Am Chem Soc 126:4108-4109

17. Brown SP, Brochu MP, Sinz CJ, MacMillan DWC (2003) J Am Chem Soc 125:10808-10809

18. Davoust M, Brière JF, Jaffrès PA, Metzner P (2005) J Org Chem 70:4166-4169 
19. Hoffmann HMR, Münnich I, Nowitzki O, Stucke H, Williams DJ (1996) Tetrahedron 52:11783-11798

20. Bloomfield JJ, Nelke JM (1977) Org Synth 57:1-7

21. Barrett AGM, Carr RAE, Finch MAW, Florent JC, Richardson G, Walshe NDA (1986) J Org Chem 51:4254-4260

22. Rathke, MW, Deitch, J (1971) Tetrahedron Lett. 2953-2956

23. Schmidt EY, Cherimichkina NA, Bidusenko IA, Protzuk NI, Trofimov BA (2014) Eur J Org Chem 4663-4670

24. Claessen RU, Kornilov AM, Banger KK, Ngo SC, Higashiya S, Wells CC, Dikarev EV, Toscano PJ, Welch JT (2004) J Organomet Chem 689:71-81

25. Bonjoch J, Bradshaw B (2012) Synlett 23:337-356

26. Lee HM, Nieto-Oberhuber C, Shair MD (2008) J Am Chem Soc 130:16864-16866

27. Oszbach G, Neszmelyi A (1990) Liebigs Ann Chem 211-212

28. Robinson RJ (1917) J Chem Soc Trans 111:762-768

29. Willstädter R, Wolfes O, Mader H (1923) Justus Liebigs Ann Chem 434:111-139

30. For a comprehensive overview see Declerck V, Martinez J, Lamaty F (2009) Chem Rev 109:1-48

31. Ocampo R, Dolbier WR Jr (2004) Tetrahedron 60:9325-9374

32. Fernandez-Ibanez MA, Macia B, Alonso DA, Pastor IM (2013) Eur J Org Chem 7028-7034

33. Wang J, Zhou RG, Wu T, Yang T, Qin QX, Li I, Yang B, Yang J (2012) J Chem Res 36:121-122

34. Sun Q, Schmidt S, Tremmel M, Heilmann J, Konig B (2014) Eur J Med Chem 85:621-628

35. Schetter B, Mahrwald R (2006) Angew Chem Int Ed 45:7506-7525

36. Woodward RB, Logush E, Nambiar KP, Sakan K, Ward DE, AuYeung $\mathrm{BW}$, Balaram $\mathrm{P}$, Browne LJ, Card $\mathrm{PJ}$, Chen $\mathrm{CH}$, Chênevert RB, Fliri A, Frobel K, Gais HJ, Garratt DG, Hayakawa
K, Heggie W, Hesson DP, Hoppe D, Hoppe I, Hyatt JA, Ikeda D, Jacobi PA, Kim KS, Kobuke Y, Kojima K, Krowicki K, Lee VJ, Leutert T, Malchenko S, Martens J, Matthews RS, Ong BS, Press JB, Rajan Babu TV, Rousseau G, Sauter HM, Suzuki M, Tatsuta K, Tolbert LM, Truesdale EA, Uchida I, Ueda Y, Uyehara T, Vasella AT, Vladuchick WC, Wade PA, Williams RM, Wong HNC, Press JB (1981) J Am Chem Soc 103:3210-3213

37. Ballini R, Petrini M, Marotta E (1989) Synth Comm 19:575-583

38. Stork G, Brizzolara A, Landesman H, Szmuszkovicz J, Terrell R (1963) J Am Chem Soc 88:207-222

39. Kosugi M, Takano I, Sakurai M, Sano H, Migita T (1984) Chem Lett 1221-1224

40. Adlington RM, Barrett AGM (1981) J Chem Soc Perkin Trans 1:2848-2863

41. Custar DW, Le H, Morken JP (2010) Org Lett 12:3760-3763

42. Stetter H (1976) Angew Chem 88:695-736

43. Aupoix A, Vo-Thanh G (2009) Synlett 1915-1920

44. Buechi G, Wuest H (1969) J Org Chem 34:1122-1123

45. Olsen RS, Fataftah ZA, Rathke MW (1986) Synth Comm 16:1133-1139

46. Cornish CA, Warren S (1985) J Chem Soc Perkin Trans. 1:2585-2598

47. Balskus EP, Méndez-Andino J, Arbit RM, Paquette LA (2001) J Org Chem 66:6695-6704

48. Stork G, Clark G, Shiner CS (1981) J Am Chem Soc 103:4948-4949

49. Seebach D, Seuring B, Kalinowski HO, Lubosch W, Renger B (1977) Angew Chem 89:270-271

50. Abe Y, Harukawa $T$, Ishikawa $H$, Miki $T$, Sumi M, Toga $T$ (1956) J Am Chem Soc 78:1416-1421 